\title{
Ius Constitutionale Commune en América Latina: una mirada a un constitucionalismo transformador ${ }^{*-* * *}$ \\ Ius Constitutionale Commune in Latin America: A look at a transformative constitutionalism
}

SUMARIO

I. Contexto y finalidad de esta contribución. II. Un nuevo enfoque del constitucionalismo latinoamericano. 1. La exclusión y la desigualdad como problemas centrales. 2. Lo común. 3. ¿Qué quiere decir latinoamericano? III. Objetivos y medios. 1. La interpretación latinoamericana de ciertos principios constitucionales. 2. Sobre el concepto de institucionalidad y el nuevo rol de los tribunales internacionales. 3. Sobre el rol de las instituciones regionales. 4. Pluralismo dialógico. Resumen.

RESUMEN

El Ius Constitutionale Commune en América Latina (ICCAL) se refiere a un enfoque regional sobre el constitucionalismo transformador. Dicho enfoque se nutre de la inquietante experiencia respecto de condiciones de vida inaceptables y apunta a la transformación de la realidad política y social de América Latina por medio del fortalecimiento concertado de la democracia, el Estado de derecho y los derechos humanos. Los problemas comunes a los países

* Ponencia presentada con ocasión del 40 Aniversario del Instituto Iberoamericano de Derecho Constitucional, 14 y 15 de mayo de 2014. Agradezco a Rodolfo Arango, Laura Clérico, Thomas Duve, Samuel Issacharof, Franz Ebert, Manuel Góngora Mera, Simon Hentrei, Mariela Morales Antoniazzi, Flavia Piovesan y Ximena Soley por sus valiosos comentarios y críticas. Igualmente expreso mi gratitud por las observaciones de MANUEL José CePedA, Jesús María Casal, Humberto Sierra, Claudio Nash, Gilbert Armijo, Víctor Bazán, Paola Acosta Alvarado, César Landa, Christian Steiner y Juan Carlos Henao, en el marco de los intercambios académicos sobre el Ius Constitutionale Commune llevados a cabo en Colombia en agosto de 2014. Traducción del alemán por Ximena Soley.

** Recibido el 14 de diciembre de 2014, aprobado el 1. ${ }^{\circ}$ de abril de 2015.

Para citar el artículo: A. BogdAndy, v. Ius Constitutionale Commune en América Latina: una mirada a un constitucionalismo transformador. Revista Derecho del Estado, n. ${ }^{\circ}$ 34, Universidad Externado de Colombia, enero-junio de 2015, pp. 3-50. DOI: 10.18601/01229893.n34.01

*** Director del Instituto Max Planck de Derecho Público Comparado y Derecho Internacional. Profesor de Derecho Público en la Universidad de Fráncfort del Meno. Contacto: bogdandy@mpil.de 
latinoamericanos, tales como la exclusión de amplios sectores de la sociedad y la débil normatividad del derecho, son temas centrales de este enfoque. El ICCAL no apuesta por la integración funcional de la región, sino más bien por un constitucionalismo regional de los derechos con garantías supranacionales. Como resultado de esto último, los representantes del ICCAL reconocen la muy estrecha relación que existe entre el derecho constitucional, el derecho internacional y el derecho comparado. La apertura de los ordenamientos jurídicos nacionales de numerosos países latinoamericanos hacia el derecho internacional, y en particular hacia el sistema interamericano de protección de los derechos humanos, es de especial importancia y constituye el núcleo normativo del ICCAL. La presente contribución analiza los elementos centrales de dicho enfoque y describe sus contornos específicamente latinoamericanos.

PALABRAS CLAVE

Ius Constitutionale Commune, constitucionalismo transformador, democracia, Estado de derecho, derechos humanos, diálogo judicial.

\section{ABSTRACT}

Ius Constitutionale Commune en América Latina (ICCAL) stands for a regional approach in transformative constitutionalism. This approach arises out of the deeply troubling experience of unacceptable living conditions and aims at changing political and social realities of Latin America through the concerted strengthening of democracy, the rule of law and human rights. Common problems, such as the exclusion of wide sectors of the population, or the weak normativity of law, are at its center. ICCAL does not place its hopes on the functional integration of the region but rather on a rights based, supranationally-secured and regionally rooted constitutionalism. As a result, ICCAL representatives insist on the close ties between constitutional, international and comparative law. In this sense, the opening of numerous national legal orders to international law and to the Inter-American System of Human Rights Protection is of particular importance as it constitutes the normative core of ICCAL. The present contribution analyzes the main elements of this approach and describes its specific Latin American Gestalt.

KEYWORDS

Ius Constitutionale Commune, transformative constitutionalism, democracy, human rights, rule of law, judicial dialogue. 


\section{CONTEXTO Y FINALIDAD DE ESTA CONTRIBUCIÓN}

Desde el año 2004, el Instituto Max Planck de Derecho Público Comparado y Derecho Internacional Público ha sido el anfitrión del Coloquio Iberoamericano $^{1}$, organizado a partir del año 2006 por Mariela Morales Antoniazzi, investigadora del Instituto para temas latinoamericanos. Las 123 sesiones del Coloquio que se han celebrado hasta ahora han servido como foro para intercambiar, comparar y contrastar las ideas de los numerosos expositores y participantes, y han generado una agenda de investigación común. El Coloquio cuenta al día de hoy con una red que comprende alrededor de 250 miembros; alrededor de él se han organizado 15 conferencias internacionales así como tres cursos de verano sobre derecho comparado; además, se han publicado 12 libros $^{2}$. Desde marzo de 2014, el Coloquio es el evento principal de la sección alemana del Instituto Iberoamericano de Derecho Constitucional ${ }^{3}$.

En el Coloquio se han abordado diversas constelaciones temáticas, pero la cuestión central ha sido el constitucionalismo transformador en América Latina $^{4}$. Se trata de superar la profunda exclusión social a la luz de la tríada derechos humanos, democracia y Estado de derecho. El Coloquio ha facilitado el análisis jurídico de este desafío bajo un enfoque tanto comparativo como internacionalista, lo que implica una serie de innovaciones. Este enfoque ju-

1 El Coloquio Iberoamericano fue creado como grupo de debate del Instituto Max Planck de Derecho Público Comparado y Derecho Internacional el 5 de febrero de 2004, gracias a la iniciativa de los doctorandos del Prof. Dieter Nohlen, Richard Ortiz Ortiz y Andrés Jouannet VALDERRAMA, apoyada por un grupo de investigadores hispanoparlantes. En el Acta constitutiva se definen los objetivos así como los procedimientos para su funcionamiento.

$2 \mathrm{http} / / / \mathrm{www} . \mathrm{mpil} . \mathrm{de} / \mathrm{en} / \mathrm{pub} / \mathrm{research} / \mathrm{details} /$ projects/comparative_law/ius_constitutionale_commune.cfm

3 Más sobre este Instituto en la sección II.

4 El concepto de constitucionalidad transformadora se conoce del constitucionalismo colombiano en el marco de la nueva Constitución de 1991. La Constitución de 1991 se identifica como un parteaguas y tiene como soporte la efectividad de los derechos humanos como uno de sus pilares fundamentales. M. J. CEPEDA ¿Cómo se hizo la Asamblea Constituyente? Introducción a la Constitución de 1991: hacia un nuevo constitucionalismo. Bogotá: Presidencia de la República, 1993, pp. 173-186; M. J. CEPEDA. Los derechos fundamentales de la Constitución de 1991. Vol. 2. Bogotá: Temis, 1997. Se afirma que los constituyentes de 1991 no solo eran depositarios de una voluntad popular ansiosa de respuestas institucionales para transformar la situación, sino que estuvieron motivados por una especial sensibilidad en lo que concierne al derecho internacional de los derechos humanos. J. C. Upegui Mesía. Cuatro indicios de la influencia de la Declaración Universal de los Derechos Humanos de 1948 en el constitucionalismo colombiano. Revista Derecho del Estado. 2009, 23, 191-212. El constitucionalismo transformador también se conoce a partir de la discusión sudafricana. Pionero en este sentido: K. KLARE. Legal Culture and Transformative Constitutionalism. South African Journal on Human Rights. 1998, 14(1), 146-188; sobre su significado, T. Roux. Transformative Constitutionalism and the Best Interpretation of the South African Constitution: Distinction without a Difference? Stellenbosch Law Review. 2009, 20(2), 258-285. 
rídico holístico se conoce cada vez más como Ius Constitutionale Commune en América Latina (ICCAL) .

La idea de un constitucionalismo latinoamericano no es nueva ${ }^{6}$. Sin embargo, el siglo XXI la ha dotado de nuevos contornos en el sentido de un Ius Constitutionale Commune. Un momento importante en la formación de su identidad lo constituye el rechazo de las tres ideologías constitucionales tradicionales latinoamericanas, a saber, el conservadurismo, el liberalismo y el radicalismo ${ }^{7}$. Sus características positivas son la combinación del derecho nacional y del internacional público, la orientación metodológica hacia principios, la centralidad de los derechos y la estrategia de perseguir transformaciones de manera incremental.

El Ius Constitutionale Commune emerge en un ámbito discursivo densamente poblado; es muy conocido, por ejemplo, el así llamado nuevo constitucionalismo latinoamericano ${ }^{8}$. Se podría decir que Latinoamérica es la región donde se discute con mayor intensidad y apremio sobre el futuro del constitucionalismo, como lo demuestran en el derecho positivo las innovadoras constituciones de Bolivia y Ecuador ${ }^{9}$. Este debate representa el contexto del

5 Sobre el concepto del Ius Constitutionale Commune, M. E. Góngora Mera. InterAmerican Judicial Constitutionalism: On the Constitutional Rank of Human Rights Treaties in Latin America through National and Inter-American Adjudication. San José: Inter-American Institute of Human Rights, 2011, p. 243; Voto razonado del juez ad hoc Eduardo Ferrer MacGregor Poisot en relación con la sentencia de la Corte Interamericana de Derechos Humanos en el caso Cabrera García y Montiel Flores vs. México, de 26 de noviembre de 2010; R. Arango. Ius constitutionale commune, El Espectador, 24 de noviembre de 2009; N. Sagüés. Obligaciones internacionales y control de convencionalidad. Estudios Constitucionales. 2010, 8(1), 117-136; S. GARCía RAmírez. El control judicial interno de convencionalidad. IUs. Revista del Instituto de Ciencias Jurídicas de Puebla. 2011, 5(28) 123-159; F. Piovesan. Proteção dos direitos sociais: desafios do ius commune sul-americano. Revista do Tribunal Superior do Trabalho. 2011,77(4), 102-139; F. Piovesan. Direitos humanos e diálogo entre jurisdições. Revista Brasileira de Direito Constitucional. 2011, 19, 67-93.

6 Para conocer la trayectoria latinoamericana se puede acudir a la edición especial de la revista Rechtsgeschichte; T. DuvE. Verfassung und Verfassungsrecht in Lateinamerika im Licht des bicentenario. Einleitung zur Debatte. Rechtsgeschichte. 2010, 16, 16; también J. M. CASAL HERNÁNDEZ. El constitucionalismo latinoamericano y la oleada de reformas constitucionales en la región andina. Rechtsgeschichte. 2010, 16,212-241.

7 R. Gargarella. Latin American Constitutionalism 1810-2010. The Engine Room of the Constitution. Oxford: oup. 2013, en particular 197 ss.

8 Sus contornos siguen siendo vagos. Para algunos, se refiere a amplios consensos después de los gobiernos autoritarios, en este sentido es similar al ICCAL. Para otros, es más bien un proyecto de izquierda. Particularmente instructivas son las obras R. VICIANO PASTOR, coord. Estudios sobre el nuevo Constitucionalismo latinoamericano. Valencia: Tirant lo Blanch, 2012; D. Nolte, D. y A. Schilling-Vacaflor, coords. New Constitutionalism in Latin America. Promises and Practices. Farnham: Ashgate, 2012; para otros, es un engaño: cfr. R. GARGARELla. El "nuevo constitucionalismo latinoamericano". El País, Madrid. 20 de agosto de 2014. Vol. 20. Disponible en: [http://elpais.com/elpais/2014/07/31/opinion/1406816088_091940.html]

9 Sobre Bolivia: A. Schilling-VACAFlor. Recht als umkämpftes Terrain. Die neue Verfassung und indigene Völker in Bolivien. Baden-Baden: Nomos, 2010, 221; sobre Ecuador: M. 
Ius Constitutionale Commune. Las similitudes entre los distintos autores que utilizan este concepto permiten hablar del Ius Constitutionale Commune como enfoque, o quizás aun como un proyecto específico. Esta contribución es un esfuerzo para aproximarse a su descripción. En ella se analizan los componentes esenciales que le prestan su nombre al Ius Constitutionale Commune en América Latina (II) así como ciertos conceptos constitucionales clave con sus propias características latinoamericanas (III).

Metodológicamente, este análisis consiste en la interpretación que un publicista alemán hace de algunos textos académicos, sobre todo de aquellos que han sido objeto de debate en el Coloquio Iberoamericano, así como de las posiciones que se han defendido en él ${ }^{10}$. Esta síntesis se guía por el deseo de captar cómo las personas asociadas al Ius Constitutionale Commune en América Latina comprenden, relacionan y desarrollan el derecho del Estado, el derecho internacional público universal, el derecho regional de la integración, el derecho comparado y la teoría política a fin de responder a los desafíos de nuestros tiempos.

La cuestión promete ser interesante ya que el constitucionalismo en América Latina tiene una tradición de más de 200 años. Es decir, la experiencia de la región en esta materia es más extensa que la de muchos Estados europeos y que la de la mayor parte de los Estados del mundo. Los aportes latinoamericanos a la idea del constitucionalismo prometen también poner a prueba el supuesto contenido universal de ciertas concepciones constitucionales del "Norte global". Además, podría ser que estos conceptos, que según algunos autores europeos muestran señas críticas de agotamiento ${ }^{11}$, cobren nueva vida y relevancia gracias a la discusión actual de los mismos en Latinoamérica ${ }^{12}$.

Góngora Mera, G. M. Herrera y C. Müller. The Frontiers of Universal Citizenship. Transnational Social Spaces and the Legal Status of Migrants in Ecuador. Disponible en: desiguALdades. net Berlin. Working Paper Series 71, 2014, 13 ss. Disponible en: http://www.desigualdades.net/ Resources/Working_Paper/71-WP-Gongora-Mera-Herrera-Mueller-Online.pdf?1396440530 ; sobre las innovaciones en estos dos países, así como en otros países latinoamericanos, G. Aguilar Cavallo, Emergencia de un derecho constitucional común en material de pueblos indígenas. En A. Bogdandy, E. Ferrer Mac-Gregor y E. Morales Antoniazzi, coords. La Justicia Constitucional y su internacionalización. Hacia un Ius Constitutionale Commune en América Latina? Vol. 2. México D.F.: unAM, 2010, pp. 3-84 (en adelante "La Justicia Constitucional y su internacionalización").987

10 Sobre cuestiones epistemológicas, T. DuvE. Internationalisierung und Transnationalisierung der Rechtswissenschaft, aus deutscher Perspektive. LOEWE Research Focus "Extrajudicial and Judicial Conflict Resolution”. Working Paper 2013, 6, 9 ss.; B. Z. Tamanaha. What is 'General' Jurisprudence? A Critique of Universalistic Claims by Philosophical Concepts of Law. Transnational Legal Theory. 201lok1, 2(3), 287-308.

11 M. Koskenniemi. Human Rights Mainstreaming as a Strategy for Institutional Power, Humanity. An International Journal of Human Rights, Humanitarianism, and Development. 2010, 1, 47; M. Koskenniemi. The Politics of International Law. Oxford: Hart, 2011, 133.

12 Sobre la contribución del Sur global para entender la realidad social y sobre la relevancia de dicha contribución para el Norte global, tomando el ejemplo de África, J. ComAROFF, y J. 
Asimismo, la experiencia latinoamericana con el fenómeno de instituciones débiles ${ }^{13}$, el cual se observa igualmente en la periferia del espacio jurídico europeo, es de larga data y podría arrojar conclusiones interesantes. Por lo tanto, la motivación para estudiar el enfoque latinoamericano no se debe solamente a un interés académico por la región, ya que dicho enfoque abarca fenómenos que también son europeos y globales ${ }^{14}$. Como bien lo demuestra la fundación de la International Society of Public Law, el entrelazamiento entre la teoría política, el derecho del Estado, el derecho comparado, el derecho de la integración y el derecho internacional público, es un tema tan actual como universal ${ }^{15}$.

¿Puede tener algún tipo de relevancia para Latinoamérica este análisis hecho por un publicista alemán? Hoy en día, cualquier "asesoramiento" europeo a Latinoamérica sobre la manera "adecuada" para organizar una sociedad despierta suspicacias ${ }^{16}$. Es más, el mero ofrecimiento de conceptos se ve con recelo en el ámbito de los estudios poscoloniales ${ }^{17}$. No obstante, numerosas sesiones del Coloquio han revelado que la descripción y conceptualización de un fenómeno, realizadas por una persona que lo observa a cierta distancia, pueden ser provechosas para quienes se encuentran más cerca del fenómeno en cuestión. Las reconstrucciones que parten de otros contextos y que se realizan a una mayor distancia pueden generar conocimiento valioso. Así es como entiendo mi rol en el ICCAL. Podemos ilustrar

ComAroff. Theory from the South. Or, how Euro-America is Evolving Toward Africa. Boulder: Paradigm Publishers, 2012, en particular 1-19.

13 B. Sissenich. Weak States, Weak Societies: Europe's East-West Gap. Acta Politica. 2010, 45(1-2), 11-40. Los datos que apoyan esta comparación se encuentran disponibles en: www.govindicators.org

14 De manera similar, en el ámbito de la historia del derecho, T. Duve Von der Europäischen Rechtsgeschichte zu einer Rechtsgeschichte Europas in globalhistorischer Perspektive. Rechtsgeschichte. 2012, 20, 18. No implica la idea de una "jurisprudencia universal"; en este sentido: H. Mohnhaupt. Historische Vergleichung im Bereich von Recht und Staat. Frankfurt am Main: Klostermann, 2000, 437 ss.; TAMANAHA, ob. cit. 12.

15 Véase la página web de The International Society of Public Law, disponible en: http:// icon-society.org/; programático: WeILER, J. The International Society for Public Law - Call for Papers and Panels. Int. J. Constitutional Law. 2014, 12, 1-3.

16 Respecto de la problemática de los Estados débiles, S. Oeter (Fragile) Staatlichkeit und Entwicklung. En P. Dann, S. Kadelbach y M. Kaltendorn, coords. Entwicklung und Recht. Baden-Baden: Nomos, pp. 471-497. La investigación histórica sugiere que nunca ha habido una transferencia unilateral de conocimiento entre Europa y otras partes del mundo; más bien las transferencias de conocimiento entre las regiones siempre han tenido carácter multi-direccional; para un resumen, véase H. WENDT y J. RENN. Knowledge and Science in Current Discussions of Globalization. En RenN, J., coord. The Globalization of Knowledge in History. Berlin: Edition Open Access, 2012, 45-72, refiriéndose en particular a A. G. FrANK. ReOrient. Global Economy in the Asian Age. Berkeley/Los Angeles: University of California Press, 1998.

17 Una aproximación a esta idea se puede encontrar en A. Draude y S. NeuwEILER. Governance in der postkolonialen Kritik. Die Herausforderung lokaler Vielfalt jenseits der westlichen Welt. SFB-Governance Working Paper Series. 2010, 25(5), 7-8. 
este punto modificando levemente una imagen descrita por Isaac Newton: para alcanzar nuevo conocimiento en un proceso de investigación común no es necesaria una ubicación más elevada, basta con una ubicación distinta ${ }^{18}$. Sin embargo, entre más alejada sea la ubicación, más precario y abstracto será el conocimiento alcanzado.

\section{UN NUEVO ENFOQUE DEL CONSTITUCIONALISMO LATINOAMERICANO}

\section{La exclusión y la desigualdad como problemas centrales}

La denominación en latín de la perspectiva, Ius Constitutionale Commune en América Latina, puede parecer vetusta, pero se refiere a un enfoque transformador. Apunta a la transformación de la realidad política y social de América Latina para crear las condiciones sociales y políticas necesarias para hacer efectiva la democracia, el Estado de derecho y los derechos humanos ${ }^{19}$. Claro está que dichos conceptos son vagos e incluso ambiguos, pero el enfoque se alimenta de experiencias muy precisas y concretas, experiencias que nutren el deseo de transformar una situación que para muchos resulta inaceptable. Por esta razón, y aquí vemos una característica específica del discurso latinoamericano, los principios a los que acá nos referimos se acentúan en su dimensión social con una intensidad que no es usual en Europa o en Canadá, por no mencionar a los Estados Unidos de América. Diferentes autores hacen del desafío de la desigualdad el punto central de su pensamiento ${ }^{20}$. Este tema ha inspirado incluso un enfoque propio de investigación interdisciplinaria ${ }^{21}$.

Pocas cuestiones sociales son tan delicadas como la cuestión de la igualdad y de la redistribución. Las opiniones al respecto son igualmente dispares. En este contexto complejo, el concepto de exclusión parece útil. La desigualdad puede ser producto de muchos factores, pero lo cierto es que resulta particularmente profunda, persistente y delicada cuando grupos enteros de personas

18 R.K. Merton. Auf den Schultern von Riesen: Ein Leitfaden durch das Labyrinth der Gelehrsamkeit. Frankfurt am Main: Suhrkamp 1983, 13 ss.

19 R. Arango. Fundamentos del Ius Constitutionale Commune en América Latina: Derechos Fundamentales, Democracia y Justicia Constitucional. A. v. En Bogdandy, H. Fix-Fierro y M. Morales Antoniazzi, coords. Ius Constitutionale Commune en América Latina. Rasgos, potencialidades y desafíos. México: unAm, 2014, 25 ss., en adelante "Rasgos". Este libro resume nuestra perspectiva y sintetiza 10 años de trabajo; disponible en: http://biblio.juridicas.unam. $\mathrm{mx} / \mathrm{libros} / \mathrm{libro} . \mathrm{htm} ? \mathrm{l}=3655$

20 F. Piovesan. Ius Constitutionale Commune en derechos humanos e impacto del sistema interamericano: Rasgos, potencialidades y desafíos. En Rasgos, ob. cit. 21, 61, 63.

21 M. Braig, S. Costa y B. GöBel. Soziale Ungleichheiten und globale Interdependenzen in Lateinamerika. Eine Zwischenbilanz. desigualdades.net (online). Berlín. Working Paper Series 4, 2013. Disponible en: www.desigualdades.net/Resources/Working_Paper/4_WP_Braig_ Costa_G__bel_Online.pdf?1371216108 Se convirtió en tema de discusión global con el libro de Thomas Picketty, Le Capital au XXIe siècle, 2013. 
no están en capacidad de participar en los grandes sistemas sociales, es decir, en los sistemas educativo, sanitario, económico y político, e incluso ni siquiera en el sistema legal. El desafío descrito se capta con el concepto de exclusión. Posibilita una perspectiva comprehensiva de sociedades cuyas capacidades de integración se encuentran en peligro cuando un gran número de personas no son tomadas en cuenta por las instituciones ${ }^{22}$. Es imposible para una sociedad aliviar la desigualdad como déficit sistémico si no logra superar semejante exclusión. Vista de esta manera, la superación de la exclusión es un proyecto compartido por concepciones con ideas muy distintas respecto de la creación de bienestar social, la redistribución, el libre comercio o la protección de las inversiones.

Expresado de manera positiva, el gran tema es la inclusión conforme a los principios constitucionales ${ }^{23}$. Si bien este concepto, en su faceta jurídica, ha sido utilizado mayormente en relación con la Convención sobre los derechos de las personas con discapacidad ${ }^{24}$, existen intentos notables para convertirlo en un concepto clave ${ }^{25}$. En términos de la concepción que se tiene de la Constitución, sugiere no solo entenderla como un mero estatuto de la organización del Estado, sino además como un documento que plasma una visión integral de la vida social en un país ${ }^{26}$.

\section{Lo común}

Como muchos términos jurídicos (derecho constitucional, derecho internacional público, derecho de familia, sin olvidar el término clásico europeo Ius Commune), el concepto Ius Constitutionale Commune en América Latina se

22 N.Luhmann. Das Recht der Gesellschaft. Frankfurt am Main: Suhrkamp, 1993, 585 ss.; Habermas, J. Zur Verfassung Europas. Ein Essay. Berlin: Suhrkamp, 2011, 54; cfr. también A. SEN. The Idea of Justice. Londres: Lane, 2009, 117, el cual, refiriéndose a Mary Wollstonecraft, habla de inclusión universal en lugar de inclusión selectiva.

23 El atractivo de este concepto es conocido por los políticos y se ha utilizado en la contienda política, por ejemplo por la Presidente argentina Cristina Fernández de Kirchner. Tal uso político no impide que la academia trate el tema de la inclusión, pues muchos conceptos constitucionales son al mismo tiempo conceptos de lucha política.

24 Cfr. J. BernstorfF. Menschenrechte und Betroffenenrepräsentation. Entstehung und Inhalt eines UN-Antidiskriminierungsübereinkommens über die Rechte von behinderten Menschen. Zä̈RV, 2007, 67, 1041.

25 P. ej., R. Stichweн. Inklusion und Exklusion. Studien zur Gesellschaftstheorie. Bielefeld: Transcript, 2005.

26 Esto podría explicar la recepción tan amplia de la obra de Häberle, si bien la academia latinoamericana en general es más crítica y consciente de lo conflictivo de su proyecto de inclusión. Sobre su influencia cfr. G. Ferreira Mendes y A. R. Vale. d. O pensamento de Peter Häberle na jurisprudência do Supremo Tribunal Federal. Observatório da Jurisdição Constitucional. 2008-2009, 2, 2, así como la introducción de D. VALAés. Peter Häberle: un jurista para el siglo XXI. Estudio introductorio, en P. HäBERLE. El Estado constitucional. México D.F.: UNAM, 2001, XXI-LXXXIV. 
refiere tanto al derecho positivo como al discurso jurídico sobre el mismo ${ }^{27}$. Referirse al fenómeno en tanto que derecho común (Ius Commune) se justifica por dos componentes esenciales del enfoque ${ }^{28}$. El primer componente consiste en la nueva apertura de los ordenamientos jurídicos estatales latinoamericanos hacia un estrato común de derecho internacional público, sobre todo hacia la Convención Americana. Aunque esta apertura se exprese únicamente en uno o pocos artículos de las constituciones ${ }^{29}$, se sostiene que tal apertura afecta y transforma la esencia del constitucionalismo. Los derechos constitucionales estatales y el derecho internacional público se encuentran en una relación de fortalecimiento mutuo, están llamados a realizar las garantías y promesas del así llamado "bloque de constitucionalidad". Esta apertura es entonces expresión de un desarrollo común, que además les confiere a los ordenamientos jurídicos estatales una orientación común. De allí que luzca muy congruente que la Corte Interamericana describa el conjunto de los tratados de derechos humanos como un corpus iuris ${ }^{30}$. Se trata asimismo de un cambio común, ya que vincular el derecho estatal con el derecho internacional público constituye una ruptura en la manera tradicional de estudiar estas dos áreas del derecho, puesto que tradicionalmente su tratamiento académico e investigación se desarrolla por separado ${ }^{31}$.

El segundo componente es un discurso común de derecho comparado ${ }^{32}$. La idea de poner el derecho constitucional comparado al servicio de fines democráticos acompaña la fundación del Instituto Iberoamericano de Derecho Constitucional en el año 1974 en Buenos Aires, producto de la colaboración entre juristas mexicanos y argentinos. El cometido inicial de Jorge CARPIZo,

27 Sobre el doble significado del "verdadero" Ius Commune y su posible significado contemporáneo, R. ZIMMERMANN. Das römisch-kanonische ius commune als Grundlage europäischer Rechtseinheit. Juristenzeitung. 1992, 8-20. Al igual que respecto del verdadero Ius Commune, el debate académico latinoamericano parece ser esencial para la creación del fenómeno en el derecho positivo. Ciertamente el concepto latinoamericano se diferencia del europeo en muchos sentidos.

28 Sobre el atractivo del concepto de Ius Commune para América Latina, J. M. SERNA DE LA GARZA. "El concepto del Ius Commune latinoamericano en derechos humanos: Elementos para una agenda de investigación", en Rasgos, ob. cit. 21, 212 ss.

29 En más detalle, abajo, III 3.

30 Se reconoce como aporte de la Corte Interamericana de Derechos Humanos al derecho internacional. Cfr. D. O'Donnel. Derecho Internacional de los Derechos Humanos. Normati$v a$, jurisprudencia y doctrina de los sistemas universal e interamericano. Bogotá: Oficina en Colombia del Alto Comisionado de las Naciones Unidas para los Derechos Humanos, 2004, 57-59. Dicho reporte también incluye la reseña sobre las decisiones de la Corte Interamericana de Derechos Humanos en donde se usa el término.

31 Pionera F. Piovesan. Direitos humanos e o direito constitucional internacional. São Paulo: Limonad, 1996; cfr. también P. NiKKEN. El Derecho Internacional de los Derechos Humanos. Revista de la Facultad de Ciencias Jurídicas y Políticas. 1989, 72, 15-52.

32 Brewer-Carías, A. Constitutional Protection of Human Rights in Latin America. A Comparative Study of Amparo Proceedings. Nueva York: Cup, 2014; E. Ferrer MAC-Gregor. Panorámica del Derecho procesal constitucional y convencional. Madrid: Pons, 2013. 
Héctor Fix-Zamudio, Pedro Frías, Diego V aladés y Jorge Vanossi fue el de establecer la comunicación entre dos ámbitos de discusión jurídica que hasta ese momento se desarrollaban por aparte, para así dar seguimiento conjunto a la idea del constitucionalismo en el difícil contexto de los gobiernos autoritarios. En cuestión de poco tiempo varios juristas de otros Estados, tales como Brasil, Venezuela, Colombia, Guatemala, Perú y Uruguay, se unieron al proyecto; hoy en día el Instituto Iberoamericano es un foro fundamental del pensamiento contemporáneo sobre el constitucionalismo ${ }^{33}$.

La intensificación del estudio comparado del derecho público como parte del proyecto transformador impulsado por el ICCAL se deja vislumbrar también en otros escenarios. En este sentido, cabe mencionar una serie de publicaciones. Desde 1989, la Revista Latinoamericana de Derechos Humanos, publicada por la Universidad Nacional de Costa Rica, se centra en el debate acerca de los derechos humanos, evidenciando así el protagonismo de este ámbito jurídico para la región. Una publicación algo más antigua es Derecho de la Integración: Revista Jurídica Latinoamericana, que se publicara de 1967 a 1978 por el Instituto para la Integración de América Latina ${ }^{34}$, afiliado al Banco Interamericano de Desarrollo. Su temática eran los aspectos jurídicos de la integración económica en América Latina, y estaba ligada a la idea de la creación de un espacio económico latinoamericano ${ }^{35}$. El Programa Estado de Derecho para Latinoamérica, de la Fundación Konrad Adenauer, publicó la XIX edición de su Anuario de Derecho Constitucional Latinoamericano dedicado al estudio y fomento de esta rama del derecho en los países de la región, con aportaciones de académicos, operadores jurídicos y jóvenes investigadores. Todos convergen hoy en día en identificar como un rasgo común la "sed de materialización garantista" de estas constituciones ${ }^{36}$.

Para ejemplificar el estudio comparado se cuenta también con la Revista Latinoamericana de Derecho, en circulación desde 2004 y publicada por el Instituto de Investigaciones Jurídicas de la Universidad Nacional Autónoma de México (UNAM). Esta revista se dedica a la investigación del derecho más allá de las fronteras nacionales en América Latina, en especial en los ámbitos que son particularmente relevantes en razón de tradiciones culturales y proyectos afines ${ }^{37}$. Otras revistas tienen como meta, al menos desde el momento de su denominación, fomentar un discurso jurídico latinoamericano, como por ejemplo la Revista Latinoamericana de Derecho Social. También

33 Recientemente XI. Congreso Iberoamericano de Derecho Constitucional "Jorge Carpizo", 17-19 de septiembre de 2013 en Tucumán, Argentina. http://www.iberoconstitucional.com.ar/

34 Hoy llamado Instituto para la Integración de América Latina y el Caribe.

35 Instituto para la Integración de América Latina, editorial, Derecho de la Integración: Revista Jurídica Latinoamericana. 11967, 1, n. . 1, 5-7.

36 G. Elsner, G. y C. Steiner. Prólogo. Anuario de Derecho Constitucional Latinoamericano. 2011, 9 .

37 A. Ventura. Presentación. Revista Latinoamericana de Derecho. 2004, 1, XI-X. 
publicada por la UNAM, tiene como finalidad dar oportunidad a los juristas mexicanos y extranjeros de crear una nueva doctrina en el ámbito del derecho social que propicie soluciones al problema de la desigualdad en las relaciones sociales ${ }^{38}$. Parece muy importante también la fundación de la Sociedad Latinoamericana de Derecho Internacional en el año 2007 para fomentar la discusión regional en tales temas ${ }^{39}$.

Todo ello evidencia el gran interés de contar con un discurso jurídico regional. No obstante, de acuerdo con las observaciones de muchos de los participantes en el Coloquio y a pesar de las facilidades lingüísticas, el discurso jurídico regional encuentra severos obstáculos. A menudo da la impresión de que el contacto con instituciones de investigación de extracción estadounidense o europea es más intenso que entre instituciones latinoamericanas. Tomando en consideración que la falta de recursos suele ser un problema en la región, la decisión del Instituto de Investigaciones Jurídicas de la Universidad Nacional Autónoma de México de dar acceso libre en línea a su amplia gama de publicaciones marca una alentadora pauta ${ }^{40}$.

\section{3. ¿Qué quiere decir latinoamericano?}

Para muchos autores es importante, y en esto hacen hincapié, que el discurso latinoamericano se inserte en el discurso universal y que no se convierta en un particularismo más ${ }^{41}$. El Ius Constitutionale Commune está muy lejos de la idea de un derecho internacional específicamente distinto en América Latina ${ }^{42}$. Así, la calificación del Ius Commune como latinoamericano no implica una distinción fundamental frente al "Norte global", pues no se esgrimen "valores latinoamericanos", como sí sucede con los supuestos "valores asiáticos"43.

38 D. Valadés. Palabras de Bienvenida. Revista Latinoamericana de Derecho Social. 2005, 1, IX-XIII.

39 Véase la página web de la Sociedad Latinoamericana de Derecho Internacional, http:// lasil-sladi.org/es/home.html

40 Disponibles en: http://www.juridicas.unam.mx/publica/. El libro Rasgos, ob. cit. 21 también ha sido publicado de esta manera.

41 S. GarCía Ramírez. La 'navegación americana' de los derechos humanos: hacia un Ius Commune. En Rasgos, ob. cit. 21, 459-491; así, la Corte Interamericana de Derechos Humanos subraya a menudo las bases universalistas de su jurisprudencia. Incluso los tribunales nacionales hacen uso de la jurisprudencia de otras regiones del mundo: M. Morales AnToniazZI. El Estado abierto como objetivo del Ius Constitutionale Commune. Aproximación desde el impacto de la Corte Interamericana de Derechos Humanos. En Rasgos, ob. cit. 21, 265, 267 ss.

42 J. L. Esquirol. Latin America. En B. Fassbender y A. Peters, coords. The Oxford Handbook of the History of International Law. Oxford: oup, 2013, 553, 562 ss.; A. BECKER LORCA. International Law in Latin America or Latin American International Law? Rise, Fall, and Retrieval of a Tradition of Legal Thinking and Political Imagination. Harvard International Law Journal. 2006, 47, 283-305. Quizás el representante más importante fue A. Alvarez. Latin America and International Law. American Journal of International Law. 1909, 3(2), 269-353.

43 A. KaPUR. Asian Values v. the Paper Tiger. Dismantling the Threat to Asian Values Po- 
Se trata más bien de la descripción de una región para la cual un discurso jurídico común podría acarrear grandes beneficios.

Al mismo tiempo, focalizar los estudios en la región latinoamericana y no interamericana excluye de su ámbito a los países de habla inglesa u holandesa de las Américas. A su vez, no haber denominado a la región "iberoamericana" excluye a España y Portugal ${ }^{44}$, mientras que la decisión de no denominarla "sudamericana" supone la inclusión de los países centroamericanos así como de México. Se trata, por tanto, de las antiguas colonias españolas y portuguesas, principalmente ${ }^{45}$. El uso del latín Ius Constitutionale Commune es seña del legado europeo, mostrando así que dicha influencia es mucho más que una mera carga histórica ${ }^{46}$.

Empero, la denominación "latinoamericana" no pretende que exista homogeneidad en la situación política, social, económica o jurídica de los diferentes países de la región ${ }^{47}$. Las diferencias entre Chile y Honduras no son menores, es más, quizás hasta sean mayores que aquellas entre Suecia y Rumanía ${ }^{48}$. Además, por distintas razones, los regímenes de integración económica ${ }^{49}$

sed by the International Criminal Court. Journal of International Criminal Justice. 2013, 11(5), 1059-1090, en particular 1063-1066; Di PLinIo, G. Rule of law / fazhi: il diritto in Cina tra wTo e Asian values. Diritto pubblico comparato ed europeo. 2011, 2, 326-338; M. C. DAvIs. Constitutionalism and Political Culture. Harvard Human Rights Journal. 1998, 11, 109-147, en particular 111-112.

44 No hay que olvidar que en España se discutió hasta los años setenta del siglo xx acerca de su pertenencia a Europa, la cual se entendía a sí misma como secular y moderna, o si más bien no sería mejor entenderla como parte de Iberoamérica, ya que al igual que en los Estados latinoamericanos el catolicismo tradicional seguía jugando un papel preponderante.

45 A pesar de que el término latinoamericano es una creación francesa del siglo XIX; sobre este tema cfr. D. VALADÉs. Formación y transformación del sistema presidencial en América Latina: Una reflexión sobre el ius commune latinoamericano. En Rasgos, ob. cit. 21, 169, 170 ss.; el objetivo político de sus orígenes no tiene hoy ninguna relevancia.

46 Sobre la influencia del derecho romano en los ordenamientos jurídicos latinoamericanos, M. d. R. GonZÁLEz. El periodo colonial y su legado. En Rasgos, ob. cit. 21, pp. 85-97. Esta contribución subraya al mismo tiempo que el derecho de los pueblos precolombinos siempre permaneció vigente.

47 Para una descripción de las grandes y crecientes diferencias, A. Malamud. El contexto del diálogo jurídico interamericano: fragmentación y diferenciación en sociedades más prosperas. En Rasgos, ob. cit. 21, 107 ss.

48 Cfr. p. ej. "El PIB per cápita", en Fondo Monetario Internacional, disponible en: http:// www.imf.org/external/pubs/ft/weo/2014/01/weodata/index.aspx Índice de Desarrollo Humano 2013. En Human Development Report PNUD, 2013, disponible en: http://hdr.undp.org/en/data

49 Estos son, entre otros, el Mercado Común del Sur (Mercosur), la Comunidad Andina de Naciones (CAN), la Asociación Latinoamericana de Integración (ALADI) y el Mercado Común Centroamericano (MCCA). La mayor parte de los países centroamericanos, junto con la República Dominicana, firmaron el Tratado de Libre Comercio entre República Dominicana, Centroamérica y los Estados Unidos de América (TLCCA-DR). Muchos países latinoamericanos han suscrito tratados de libre comercio a nivel bilateral con países dentro y fuera de América Latina. El líder regional en este sentido es Chile, con más de 15 tratados bilaterales de libre comercio. Cfr. la base de datos sobre tratados comerciales de la Organización Mundial de Comercio; disponible 
son débiles y cuentan con un pobre potencial de desarrollo. Cabe mencionar que estas iniciativas de integración no se dirigen a una sola comunidad latinoamericana sino más bien halan a los países en direcciones distintas ${ }^{50}$. La apuesta económica de México no puede entenderse sin el NAFTA/TLCAN, el acuerdo de integración económica más pujante del espacio latinoamericano, el cual aparta a México del espacio latinoamericano. Pero también la Alianza del Pacífico, fundada en junio de 2012 entre Chile, Colombia, México y Perú, se dirige más bien hacia Asia y la cuenca del Pacífico y se ve cada vez más como contrapeso del Mercosur (Argentina, Brasil, Uruguay, Paraguay y Venezuela) ${ }^{51}$. Reconociendo el estado de las cosas, el Ius Constitutionale Commune no tiene como objeto la integración económica y política de Latinoamérica al estilo europeo, tampoco tiene como objeto la formación de un bloque regional ni, mucho menos, la vieja idea de un gran Estado regional ${ }^{52}$.

El núcleo del Ius Constitutionale Commune es distinto. Se trata de asegurar a nivel regional la implementación de las decisiones y el cumplimiento de las promesas centrales de las constituciones estatales, sobre todo de aquellas realizadas tras los gobiernos autoritarios de la década de los años setenta y ochenta del siglo pasado. El gran problema es que los ordenamientos jurídicos y las estructuras reales de poder no se han ajustado a estas decisiones y promesas constitucionales, es decir, ha habido poco cambio en este sentido $^{53}$. Por lo tanto, a la luz de esta situación, no resulta sorprendente la débil normatividad de las disposiciones legales con un componente social $\mathrm{u}$ orientadas hacia la inclusión.

El debate que se ha generado con miras a garantizar a escala regional la realización de las promesas centrales de las constituciones estatales es el origen del enfoque conocido como Ius Constitutionale Commune en América Latina; este concepto le otorga un nombre y le aporta una idea central. Aún está por verse si dicho concepto y enfoque prevalecerá, es decir, si llegará a ser aceptado de manera generalizada. Si lograra fomentar el debate para entender y desarrollar el fenómeno jurídico sería ya un éxito. En este sentido, sus funciones se asemejan a las propias de una serie de conceptos, como por

en: http://rtais.wto.org/UI/PublicSearchByMemberResult.aspx?MemberCode=152\&lang=1\&r edirect $=1$

50 Más en detalle, MaLAMUd, en Rasgos, ob. cit. 21, 114 ss., el cual de manera ilustrativa identifica 20 mecanismos distintos de cooperación regional.

51 J. BRICEÑo RuIz. Ejes y modelos en la etapa actual de la integración económica regional en América Latina. Estudios internacionales (online). Santiago, agosto de 2013, 45(175), 9-39. Disponible en: http://www.scielo.cl/scielo.php?script=sci_arttext\&pid=S071937692013000200001\&lng=es\&tlng=es. 10.5354/0719-3769.2013.27352

52 R. Grote. Los esfuerzos integradores en el contexto histórico suramericano. En A. v. Bogdandy, C. LANDA ARroyo y M. Morales Antoniazzi, coords. Integración suramericana a través del Derecho? Un análisis interdisciplinario y multifocal. Madrid: Centros de Estudios Políticos y Constitucionales, 2009, 3 ss.

53 Gargarella, ob. cit. 9, vii, 157 ss., 200 ss. 
ejemplo, el nuevo Ius Commune en Europa ${ }^{54}$, el Ius Publicum europeo ${ }^{55}$, o bien, refiriéndonos a conceptos de corte más global, el así llamado derecho de la humanidad ${ }^{56}$, derecho cosmopolita ${ }^{57}$, derecho global ${ }^{58}$, derecho mundial ${ }^{59}$, derecho mundial interno ${ }^{60}$, derecho transnacional ${ }^{61}$ o transconstitucionalismo ${ }^{62}$. Todos ellos tienen varias características en común: promueven la inserción de los ordenamientos jurídicos estatales en contextos más amplios, subrayan la función intra-estatal, es decir doméstica, del derecho internacional, y proveen una idea que orienta la transformación. Esto es importante: los mencionados conceptos no tienen una vocación meramente académica sino también práctica, en especial cuando ingresan al ordenamiento jurídico por medio de detalladas construcciones doctrinarias. Procuran orientar en la enrevesada situación actual, estructurar y generar comunicación y dotar de sentido a las construcciones doctrinarias capaces de convertir promesas y garantías en realidad.

\section{OBJETIVOS Y MEDIOS}

\section{La interpretación latinoamericana de ciertos principios constitucionales}

Los principios fundamentales que orientan al Ius Constitutionale Commune son universales. Se trata sobre todo del respeto de los derechos humanos, la democracia y el Estado de derecho. No obstante, el objetivo principal no es participar en un discurso global sobre principios abstractos. Más bien, el enfoque se nutre de experiencias concretas, de situaciones humanas inacep-

54 De manera programática, H. CoING. Die europäische Privatrechtsgeschichte der neueren Zeit als einheitliches Forschungsgebiet. Probleme und Aufbau. Ius Commune. 1967, 1, 1-33. ZIMMERMANN, ob. cit.

55 A. v. Bogdandy y S. Hinghofer-Szalkay. Das etwas unheimliche Ius Publicum Europaeum. Begriffsgeschichtliche Analysen im Spannungsfeld von europäischem Rechtsraum, droit public de l'Europe und Carl Schmitt. ZaöRV. 2013, 73(2), 209, con una explicación de las funciones patentes y ocultas del concepto.

56 A. A. CANÇADO TRINDADE. International Law for Humankind. Towards a New Jus Gentium (I). Recueil des cours, t. 316 (2005), 9-439; International Law for Humankind. Towards a New Jus Gentium (II). Recueil des cours, t. 317, 2005, 9-312; C. W. Jenks. The Common Law of Mankind. Londres: Stevens \& Sons, 1958.

57 S. Benhabib. The Philosophical Foundations of Cosmopolitan Norms. En BenHabib, S. y POST, R. coords. Another Cosmopolitanism. Oxford: oup, 2006, 13.

58 R. Domingo. The New Global Law. Cambridge: cup, 2010.

59 M. Delmas-Marty. Trois défis pour un droit mondial. Paris: Seuil, 1998.

60 J. Habermas. Der gespaltene Westen: Kleine politische Schriften. Frankfurt am Main: Suhrkamp, 2004, 143, 159 ss.

61 P. C. Jessup. Transnational Law. New Haven: Yale University Press, 1956.

62 M. Neves. Transconstitucionalismo. São Paulo: wMF Martins Fontes, 2009. 
tables a raíz de déficits sistémicos ${ }^{63}$. El Ius Constitutionale Commune tiene una vocación sumamente práctica: hacer realidad las promesas y garantías de las constituciones latinoamericanas nuevas o reformadas después de la era de los gobiernos autoritarios. Los textos que se producen bajo la bandera del Ius Constitutionale Commune respiran un aire idealista: a pesar de los ya conocidos problemas que padece el constitucionalismo en Latinoamérica, aún se le atribuye al derecho constitucional un potencial emancipador ${ }^{64}$. Ante las considerables discrepancias entre los textos constitucionales y convencionales y la realidad, los autores no reaccionan con cinismo, resignación o ilusamente, sino más bien aceptan los desafíos que la situación presenta ${ }^{65}$.

El eje del Ius Constitutionale Commune son los derechos fundamentales y humanos ${ }^{66}$; a menudo se habla del Ius Constitutionale Commune como un Ius Constitutionale Commune en derechos humanos ${ }^{67}$. Tres razones principales lo explican. En primer lugar, el contenido transformador de las constituciones se plasma principalmente en las disposiciones sobre derechos fundamentales. En segundo lugar, estos derechos son la piedra angular de la movilización de la sociedad civil ${ }^{68}$. Por último, son las sentencias judiciales sobre derechos fundamentales y humanos, a menudo producto de la lucha de grupos sociales, las que dotan al Ius Constitutionale Commune con una energía de carácter específicamente jurídico. Hoy en día parece indudable que tales derechos ya han tenido un impacto fuerte y probablemente transformador en América Latina: aunque su garantía efectiva no siempre es una realidad, los derechos han proporcionado un lenguaje común -jurídico, pero también político y social- que antes no existía para debatir los retos y los estándares, no solo entre juristas, sino también en el discurso político y público.

63 Sobre el concepto de déficit sistémico cfr. A. v. BogDANDY y M. IoANNIDIs. La deficiencia sistémica en el Estado de Derecho. Qué es, qué se ha hecho y qué se puede hacer. Revista de Estudios Políticos. 2014, 165, 19-64.

64 Posición que en América Latina no necesariamente es compartida por todos. Cfr. el análisis del asesor legal del Presidente Salvador Allende, E. Novoa Monreal. El derecho como obstáculo al cambio social. México/Buenos Aires: Siglo xxI, 1980, 118-140.

65 H. Fix-Fierro. Epílogo. En: Rasgos, ob. cit. 21, 501; sobre el papel constructivo del pensamiento utópico en el derecho Peters, A. Realizing Utopia as a Scholarly Endeavour. EJIL. $2013,24,533$.

66 Según la dogmática jurídica alemana, los derechos fundamentales son aquellos que están previstos en la Constitución, mientras que los derechos humanos están previstos en los tratados internacionales. En el debate latinoamericano no se hace esta distinción: cfr. SALAZAR, ob. cit., p. 42.

67 Piovesan, en Rasgos, ob. cit. 21; García Ramírez, en Rasgos, ob. cit. 21.

68 E. Tramontana. La participación de las ONG en el Sistema Interamericano de Protección de los Derechos Humanos: avances, desafíos y perspectivas. En A. v. BogdANDY, E. FerRer MACGregor y M. Morales ANTONIAZZI, coords. La Justicia Constitucional y su Internacionalización. Vol. 2. México D.F.: UNAM, 2010, 533-556, en particular 538-540. 
Los derechos del Ius Constitutionale Commune, no obstante su anclaje universal, muestran una serie de características específicas ${ }^{69}$. La primera es la importancia de grandes injusticias, sobre todo de la violencia ${ }^{70}$. Esto explica algunas innovaciones latinoamericanas que han sido acogidas internacionalmente, tales como la prohibición de amnistías por violaciones graves de derechos humanos ${ }^{71}$, el feminicidio ${ }^{72}$ y la desaparición forzada de personas $^{73}$, así como la protección especial que se le ha dado a migrantes ${ }^{74}$, pueblos indígenas ${ }^{75}$ y personas afrodescendientes ${ }^{76}$.

Otra característica del desarrollo latinoamericano de los derechos humanos se explica en razón de la exclusión que diversos grupos desfavorecidos sufren en la región. Un rasgo distintivo del pensamiento de muchos de los autores del ICCAL es la insistencia en que se cumplan las promesas que desde la revolucionaria Constitución mexicana de 1917 se han hecho a los pueblos latinoamericanos ${ }^{77}$. La indivisibilidad e interdependencia de los derechos humanos, en particular de los derechos civiles respecto de los sociales, es

69 Este ámbito en particular fue impulsado de manera temprana por América Latina: HuHLE, R. Lateinamerika und die Entstehung des internationalen System des Menschenrechtsschutzes. Nürnberg: Nürnberger Menschenrechtszentrum, 2007. Disponible en: http://www.nmrz.de/wpcontent/uploads/2009/11/Lateinamerika_menschenrechtsschutzes.pdf

70 La teoría con tal base en K. GüNTHER. The Legacies of Injustice and Fear: A European Approach to Human Rights and their Effects on Political Culture. En P. Alston, coord. The EU and Human Rights. Oxford: oup, 1999, 117.

71 Corte Interamericana de Derechos Humanos, Barrios Altos (Chumbipuma Aguirre y otros vs. Perú), Sentencia de 14 de marzo de 2001, Fondo, Serie C, n. ${ }^{\circ} 75$. Veáse también Almonacid Arellano y otros vs. Chile. Excepciones Preliminares, Fondo, Reparaciones y Costas. Sentencia de 26 de septiembre de 2006. Serie C n. ${ }^{\circ}$ 154; La Cantuta vs. Perú. Interpretación de la Sentencia de Fondo, Reparaciones y Costas. Sentencia de 30 de noviembre de 2007. Serie C, n. ${ }^{\circ}$ 173; Gomes Lund y otros ("Guerrilha do Araguaia") vs. Brasil. Excepciones Preliminares, Fondo, Reparaciones y Costas. Sentencia de 24 de noviembre de 2010. Serie C, n. ${ }^{\circ} 219$; Gelman vs. Uruguay. Fondo y Reparaciones. Sentencia de 24 de febrero de 2011 Serie C, n. ${ }^{\circ} 221$.

72 Corte Interamericana de Derechos Humanos, González y otras ("Campo Algodonero") vs. México, Sentencia de 16 de noviembre de 2009, Excepción Preliminar, Fondo, Reparaciones y Costas, Serie C, n. ${ }^{\circ} 205$.

73 Corte Interamericana de Derechos Humanos, Velásquez Rodríguez vs. Honduras, Sentencia de 29 de julio de 1988, Fondo, Serie C, n. ${ }^{\circ}$ (como leading case).

74 Corte Interamericana de Derechos Humanos, Niñas Yean y Bosico vs. República Dominicana, Sentencia de 8 de setiembre de 2005, Excepciones Preliminares, Fondo y Reparaciones, Serie C, n. ${ }^{\circ} 130$.

75 Corte Interamericana de Derechos Humanos, Comunidad Mayagna (Sumo) Awas Tigni) vs. Nicaragua, Sentencia de 31 de agosto de 2001, Fondo, Reparaciones, y Costas, Serie C, n. ${ }^{\circ}$ 66; Corte Interamericana de Derechos Humanos, Comunidad indígena Yakye Axa vs. Paraguay, Sentencia de 17 de junio de 2005, Serie C, n. ${ }^{\circ}$ 125; L. Burgourge y A. Úbeda De Torres. The Inter-American Court of Human Rights: Case Law and Commentary. Oxford: oup, 2011, 500 ss.

76 A. Dulitzky. When Afro-Descendants Became Tribal Peoples. UCLA Journal of International Law and Foreign Affairs. 2010, 15, 29-82.

77 J. M. Serna De la Garza. The Constitution of Mexico. A Contextual Analysis. Oxford: Hart, 2013, 15 ss., 163 ss. 
subrayada ${ }^{78}$. Así, el derecho y los tribunales deberían estar también al servicio de los grupos sociales marginalizados.

Por esta razón el principio de igualdad no se comprende como mera prohibición de la discriminación. Requiere más bien el reconocimiento, así como la superación, de al menos las formas más grotescas de desigualdad social, y en consecuencia una cierta redistribución por parte de un Estado social ${ }^{79}$.

Este énfasis en la inclusión explica, de manera emblemática, la jurisprudencia de la Corte Constitucional de Colombia la cual, gracias a su cariz social ${ }^{80}$, es conocida a lo largo del mundo ${ }^{81}$, habiendo sido su labor reiteradamente reconocida como ejemplar en el marco del Ius Constitutionale Commune. Utilizando notables innovaciones jurídicas, la Corte intenta aplicar los derechos sociales en un contexto difícil, es decir, a pesar de no contar con una legislación o administración social desarrollada ${ }^{82}$.

Otro elemento distintivo de los derechos humanos en América Latina es el énfasis en la dimensión colectiva en la protección de derechos fundamentales. A menudo las sentencias conciernen expresamente al tratamiento que se le da a un grupo específico. En otras ocasiones se redactan de manera que se resuelve directamente sobre aspectos que afectan a ciertos grupos, lo cual termina beneficiándolos ${ }^{83}$. El carácter colectivo se refuerza debido a que

78 A. v. Bogdandy, H. Fix-Fierro y M. Morales Antoniazzi, coords. Construcción y papel de los derechos sociales fundamentales. Hacia un ius constitucionale commune en América Latina. México: UnAm, 2011.

79 L. Clérico y M. Alado. De la inclusión como igualdad en clave de redistribución y reconocimiento. Rasgos, potencialidades y desafíos para el derecho constitucional interamericano. En Rasgos, ob. cit. 21,219 ss.; J. CARPIZO. Perspectiva de la protección de los derechos humanos en el México de 2010. En H. FiX-Zamundio y D. Valadés, coords. Formación y perspectivas del Estado latinoamericano en derechos humanos y en México. México: unAM, 2010, 98 ss. Véase también V. ABRAMOVICH y C. CourTis. Los derechos sociales como derechos exigibles. Madrid: Trotta, 2002.

80 Entre tantos, E. MuÑoz Cifuentes. El constitucionalismo de la pobreza. Revista Xurídica da Universidade de Santiago de Compostela. 1995, 4(2), 53-78.

81 C. Escobar García. La defensa judicial de la Constitución en el constitucionalismo colombiano. Balances y perspectivas después de dos décadas. Foro Revista de Derecho. 2009, 12, 127-180; M. J. CEPEDA. La defensa judicial de la Constitución. La gran fortaleza colombiana. En A. v. Bogdandy, F. Piovesan y M. Morales Antoniazzi, coords. Direitos Humanos, Democracia e Intregração Jurídica na América do Sul. Rio de Janeiro: Lumen Juris, 2009, 581-628.

82 N. Osuna. Panorama de la justicia constitucional colombiana. En A. v. Bogdandy, E. Ferrer Mac-Gregor y M. Morales Antoniazzi, coords. La Justicia Constitucional y su internacionalización. Vol. 1. México D.F.: unAm, 2010, 623-643.

83 Piovesan, en Rasgos, ob. cit. 21,67 ss.; Clérico/Alado, en Rasgos, ob. cit. 21, 237 ss. Corte Interamericana de Derechos Humanos, Caso de los "Niños de la Calle" (Villagrán Morales y otros) vs. Guatemala, Sentencia de 19 de noviembre de 1999 (Fondo), Serie C, n. ${ }^{\circ}$ 63, párr. 164; Corte Interamericana de Derechos Humanos, Caso de González y otras. ("Campo Algodonero") vs. México, Sentencia de 16 de noviembre de 2009, Excepción Preliminar, Fondo, Reparaciones y Costas, Serie C n. $^{\circ}$ 205, párr. 282, 284, 39; Corte Interamericana de Derechos Humanos, Caso de las Niñas Yean y Bosico vs. República Dominicana, Sentencia de 8 de setiembre de 2005, Excepciones Preliminares, Fondo y Reparaciones, Serie C, n. ${ }^{\circ}$ 130, párrs. 109(9), 134, 138. 
muchos casos paradigmáticos son fruto de estrategias de litigio de grupos y organizaciones no gubernamentales que abogan por la transformación social ${ }^{84}$.

Si bien el proyecto tiene como objetivo una transformación fundamental, la juridicidad del enfoque así como su concentración en los derechos humanos evidencian un profundo escepticismo ante los grandes proyectos políticos. La transformación real e incremental es un rasgo distintivo de la perspectiva del ICCAL. Nadie apuesta por soluciones rápidas o revolucionarias y muchos se centran en el arduo proceso que implica una jurisprudencia transformadora.

Este escepticismo también permea la comprensión que se tiene del principio democrático. En el plano abstracto los textos del Ius Commune no se diferencian de manera significativa de los bien conocidos textos del "Norte global" ${ }^{85}$. Sin embargo, la lección de la antropología escéptica ha sido internalizada aún más profundamente y ha dado como resultado importantes desarrollos. Determina sobre todo el tratamiento del presidencialismo, el eje central del discurso latinoamericano sobre la organización del Estado ${ }^{86}$.

Una respuesta típica en la región para hacer frente a la exclusión es el presidencialismo plebiscitario ${ }^{87}$, que se dirige principalmente a los ciudadanos excluidos. La conocida debilidad de las instituciones estatales, los bien organizados y obstinados grupos de poder, así como la gran presión por resolver los problemas que padecen distintos países en Latinoamérica, justifica para muchos una centralización extrema del poder público ya que se considera la única manera de emprender y realizar reformas. En contraste, para los representantes del Ius Constitutionale Commune, esta estrategia de inclusión, también denominada "hiperpresidencialismo", no solo es incapaz de solucionar los problemas sino que más bien los agudiza ${ }^{88}$. El hiperpresidencialismo obstaculiza otros aspectos importantes del gobierno democrático: la representación parlamentaria, la deliberación, así como la separación de poderes y el reparto de las competencias. La centralización del poder tampoco es compatible con la democratización de la sociedad implícita en los amplios

84 O. PARRa Vera. El impacto de las decisiones interamericanas. Notas sobre la producción académica y una propuesta de investigación en torno al "empoderamiento institucional". En Rasgos, ob. cit. 21, 383, 393 ss.; E. CARDOsos. Litígio Estratégico e Sistema Interamericano de Direitos Humanos. Belo Horizonte: Editora Forum, 2012.

85 Cfr. Arango, en Rasgos, ob. cit. 21,31 ss.; J. CARPizo. Concepto de democracia y sistema de gobierno en América Latina. México D.F.: UNAM, 2007.

86 Cfr. J.CARPIzo. El presidencialismo mexicano. México: Siglo xxi Editores, 1979; el libro cuenta con 16 ediciones y ha sido traducido a varios idiomas, inclusive al alemán: J. CARPIZo. Das mexikanische Präsidialsystem. Múnich: Eberhard, 1987.

87 Diego Valadés considera que la fuente de inspiración del presidencialismo es la experiencia francesa y su Constitución de 1848, y no la estadounidense: VAlADÉs, en Rasgos, ob. cit. $21,176,182$.

88 Precisamente ese es el leitmotiv del libro de Gargarella, ob. cit. 9. 
catálogos de garantías fundamentales. Además, la marcada personalización de la institucionalidad es altamente perjudicial para la misma ${ }^{89}$.

Así, el Ius Constitutionale Commune ve poco prometedor el énfasis en elementos de democracia directa, como por ejemplo la elección popular de los jueces ${ }^{90}$. El ICCAL tiende más bien hacia la representatividad y la deliberación, con el fin de fortalecer la institucionalidad.

\section{Sobre el concepto de institucionalidad y el nuevo rol de los tribunales internacionales}

El concepto de institucionalidad es particularmente útil para entender el constitucionalismo latinoamericano. Este término, que no tiene equivalente directo en Europa, se menciona con asidua regularidad en los seminarios del Coloquio, en especial para subrayar las diferencias con la situación alemana, principalmente respecto de las discrepancias habituales entre los textos constitucionales y la realidad constitucional. De acuerdo a la comprensión que se tiene de la Constitución en Alemania, los principios y garantías de la misma determinan, con un alto grado de confiabilidad, el marco del ordenamiento jurídico así como las relaciones sociales. Muchos países latinoamericanos no gozan de una situación similar, lo cual frecuentemente es descrito como una falta de institucionalidad.

Sin embargo, no hay que olvidar que la situación alemana tampoco es típica en Europa. Ni siquiera los principios constitucionales del artículo 2 del Tratado de la Unión Europea (TUE) tienen una normatividad similar a los principios constitucionales alemanes ${ }^{91}$. Al mismo tiempo, cabe recalcar que algunos países latinoamericanos, en especial Chile, Costa Rica y Uruguay, superan a ciertos países europeos, como por ejemplo Bulgaria, Grecia, Italia o Rumanía, en los indicadores del Estado de derecho ${ }^{92}$. No obstante

89 D. Nohlen. Caudillismo, nación/nacionalismo e integración. En Bogdandy/Landa/ Morales, ob. cit. 54, 35 ss., de gran significancia en la decisión de la Corte Constitucional de Colombia, la cual con una argumentación audaz rechazó la posibilidad de una segunda reelección: cfr. Corte Constitucional de Colombia, sentencia C-141 de 26 de febrero de 2010; G. D. J SiERra CADENA. La Justicia constitucional en la era de la gobernanza (Un análisis de perspectiva comparada desde la periferia del derecho). Universitas. Revista de Filosofía, Derecho y Política. 2011, 13, 67-95. Una muestra de institucionalidad es el acatamiento de la decisión por parte del Presidente afectado por la misma.

90 Artículos 182, 188, 194, 198 de la Constitución boliviana; desde el punto de vista del nuevo constitucionalismo, J. GonZÁlez Quevedo. Bases jurídicas para el empoderamiento político en los actuales diseños constitucionales de Venezuela, Ecuador y Bolivia. En: PASTOR, ob. cit. 10, 269 ss.; más crítico, J. A. Rivera SANTIBÁNEZ. La justicia constitucional en el nuevo modelo de Estado boliviano. en Bogdandy/Landa/Morales, ob. cit. 11,645 ss.

91 Cfr. J. Barroso. Discurso sobre el estado de la Unión 2013. Sesión plenaria del Parlamento Europeo. Estrasburgo, 11 de setiembre de 2013. Disponible en: http://europa.eu/rapid/ press-release_SPEECH-13-684_es.htm

92 Worldwide Governance Indicators. Banco Mundial, 2014. Palabra clave: rule of law, 
lo anterior, los déficits sistémicos ocurren con mayor frecuencia en Latinoamérica y además son un tema recurrente ${ }^{93}$. En la región, la normatividad del derecho a menudo es precaria y el entramado estatal preocupantemente débil ${ }^{94}$. Un desafío constante es la falta de institucionalidad, es decir, la falta de diferenciación entre un cargo público y su titular; la corrupción es una expresión evidente de un fenómeno que, cuando alcanza a ser sistémico, corroe el Estado de derecho ${ }^{95}$. Entonces, el núcleo del concepto de institución se puede resumir de la siguiente manera: una institución se compone de prácticas sociales firmemente establecidas, prácticas que transcurren en su mayor parte independientemente de los individuos que ocupan el cargo ${ }^{96}$.

El fomento de la institucionalidad y en consecuencia de la normatividad del derecho es una aspiración central para los representantes del Ius Constitutionale Commune. Una de las convicciones fundamentales del enfoque es que, a pesar de los posibles conflictos que la interacción entre el Estado de derecho, los derechos humanos y la democracia puedan ocasionar, al fin y al cabo estos solo pueden realizarse en su conjunto ${ }^{97}$. En particular se valora la separación de poderes y la independencia de las instituciones en oposición al hiperpresidencialismo.

Esto explica la trascendencia de la figura del Ombudsman que Jorge Carpizo introdujo en el ordenamiento jurídico mexicano. Otro ejemplo importante para la realización de la democracia es el establecimiento de instituciones independientes para llevar a cabo y supervisar el proceso electoral. La creación de dichos organismos se remonta a 1924 cuando Uruguay y Chile crearon la Corte Electoral y el Tribunal Calificador de Elecciones, respectivamente ${ }^{98}$. Poco a poco, todos los países de la región fueron creando instituciones

2012, disponible en: http://info.worldbank.org/governance/wgi/index.aspx\#home ; The World Justice Project, 2014, disponible en: http://worldjusticeproject.org/sites/default/files/files/ wjp_rule_of_law_index_2014_report.pdf

93 Desde la perspectiva de la teoría de sistemas, M. Neves. La concepción del Estado de derecho y su vigencia prática en Suramérica. En: Bogdandy/LANDA/MoRales, ob. cit., 54, 53 ss.; más en detalle, Neves, M. Verfassung und Positivität des Rechts in der peripheren Moderne. Eine theoretische Betrachtung und Interpretation des Falls Brasilien. Berlin: Duncker und Humblot, 1992.

94 Cfr., p. ej., M. García Villega. Ineficacia del derecho y cultura del incumplimiento de reglas en América Latina. En: C. Rodríguez Garavito. El derecho en América Latina. Un mapa para el pensamiento jurídico del siglo XXI. Buenos Aires: Siglo XXI, 2011, 161-184.

95 En este tema también hay grandes diferencias: cfr. las estimaciones del Worldwide Governance Indicators Project, cit. 94; así como en: www.govindicators.org Algunos Estados latinoamericanos están en mejor situación que algunos Estados europeos; SisSENICH, ob. cit., 15, $11-40$.

96 Sobre la escasez de confianza, D. NoHLEn. Demokratie ohne Vertrauen: Herausforderung für die Zivilgesellschaft in Lateinamerika. Internationale Politik und Gesellschaft. 2004, 80-106.

97 Salazar, en Rasgos, ob. cit. 21,38.

98 S. Issacharoff, Fragile Democracies: Constitutional Courts in the Breach. 2014 (en 
electorales especializadas y al menos nominalmente independientes de los poderes clásicos ${ }^{99}$. En el lapso de noventa años, estos organismos han adquirido mayor independencia (la cual en muchas ocasiones era meramente nominal), mayores funciones (p. ej.: la elaboración del registro electoral y en ocasiones civil, la regulación de partidos políticos y su financiación), así como una mayor legitimidad institucional ${ }^{100}$. La contribución de los organismos electorales a la transparencia del sufragio dotó a las contiendas electorales de algunos países de mayor credibilidad y condujo a una mayor receptividad del sistema político ${ }^{101}$. Este mecanismo institucional es fundamental para avanzar el proyecto del ICCAL.

La insistencia de los representantes del Ius Constitutionale Commune en crear nuevas instituciones de protección jurídica evidencia un cierto recelo hacia el poder judicial estatal. La verdad es que, aunque algunos tribunales sean altamente reconocidos y resulten actores clave de las transformaciones constitucionales, el poder judicial en general goza de poca credibilidad. No obstante, todos los tribunales son llamados a jugar un papel importante en dicha transformación. Con este objetivo en mente se han creado o fortalecido instituciones jurisdiccionales. La jurisprudencia de la Corte Constitucional de Colombia y de la Corte Interamericana de Derechos Humanos demuestra que semejante rol para los tribunales no es una idea utópica. El énfasis en el poder judicial como motor de innovaciones transformadoras es algo nuevo en Latinoamérica. Por eso, muchas sentencias que bajo el viejo paradigma parecerían un activismo judicial cuestionable, se entienden bajo el nuevo paradigma como propios del poder judicial en una democracia constitucional que de manera incremental ayuda a realizar el nuevo proyecto constitucional.

Sin duda, las sentencias de los tribunales pueden transformar una sociedad únicamente si esta transformación está respaldada y es promovida por importantes grupos sociales. Además, los representantes del ICCAL son conscientes de que los tribunales no apoyan automáticamente un proyecto transformador ${ }^{102}$, ya sea porque no pueden o porque no quieren, a pesar de que el ideal de protección judicial de los derechos humanos cuenta con una

prensa), 165. La importancia del modelo uruguayo se subraya en el manuscrito de Issacharoff, así como en M. Fiallos Oyanguren. Los organismos electorales en el proceso de consolidación democrática en América Latina. En J. Pretelt y J. M. Ramírez, comps. Democracia política y electoral en América Latina. Bogotá: Universidad Sergio Arboleda, OEA, 2000, 348.

99 J. JARAMillo. Los órganos electorales supremos. En D. Nohlen, et al., comps. Tratado de derecho electoral comparado de América Latina. Vol. 2, México D.F.: IIDH, 2007, 372.

100 P. Martínez Ruano, Los modelos latinoamericanos y europeos de control electoral. Revista Derecho Electoral. 2102, 13, 180-181.

101 No obstante, no en todos los países hubo un fortalecimiento de la democracia después de la creación de organismos electorales independientes. Para un resumen sobre el récord mixto de la región, cfr. JARAMILLO, ob. cit. 101, 410, 419-423.

102 Salazar, en Rasgos, ob. cit. 21, 43 ss., 48 ss.; FiX-Fierro, en Rasgos, ob. cit. 21, 502. 
larga y rica tradición regional que se remonta a los inicios del siglo XIX ${ }^{103}$. Un tema recurrente es cómo hacer para que los tribunales latinoamericanos, que tradicionalmente no encaran al poder ejecutivo ni le hacen frente a la desigualdad, acepten esta ardua tarea exitosamente. La investigación en materia de justicia muestra que los tribunales, tanto nacionales como internacionales, pueden perseguir los más diversos proyectos ${ }^{104}$. Los representantes del ICCAL conocen bien los peligros de una estrategia enfocada en los tribunales: en Venezuela, la Sala Constitucional del Tribunal Supremo de Justicia, bajo la influencia del Presidente CHÁvEZ, desmanteló metódicamente ciertas garantías del Estado de derecho ${ }^{105}$.

Existe también el peligro de que los tribunales empleen sus nuevas competencias y libertades argumentativas de manera disfuncional, lo cual puede resultar en una falta de seguridad jurídica o bien en el patrocinio de intereses ajenos al derecho ${ }^{106}$. No es fácil desarrollar discursos de aplicación convincentes sobre los derechos humanos o principios constitucionales abstractos en la tradición jurídica latinoamericana, más bien conocida por su formalismo; la creación de una cultura argumentativa justificatoria toma su tiempo. Este desafío quizás explica la sorprendente recepción de RoBERT AlEXY en América Latina $^{107}$. Su teoría sobre principios y argumentación aclara, de manera aún más precisa que RONALD DWORKIN ${ }^{108}$, las fórmulas argumentativas a las que los tribunales pueden recurrir para cumplir cabalmente con su nuevo rol. Al mismo tiempo, ALEXY muestra que una orientación basada en los derechos humanos y los principios no necesariamente implica pérdidas de racionalidad ${ }^{109}$.

103 Sobre la historia y las funciones del amparo, Ferrer MACGregor, en Rasgos, ob. cit. $21,303 \mathrm{ss}$.

104 R. HIRSCHL. Towards Juristocracy. The Origins and Consequences of the New Constitutionalism. Cambridge: Harvard University Press 2004, en particular 100-148. Sobre los objetivos de los tribunals internacionales: Y. SHANY. Assessing the Effectiveness of International Courts: A Goal-Based Approach. American Journal of International Law. 2012, 106(2), 225-270, en particular 243-248.

105 De manera insistente y detallada, A. BRewer-CARías. Crónica sobre la "in" justicia constitucional. La Sala Constitucional y el autoritarismo en Venezuela. Caracas: Jurídica Venezolana, 2007.

106 Salazar, en Rasgos, ob. cit. 21, 53 ss.

107 R.ARANGo. Derechos, constitucionalismo y democracia. Bogotá: Universidad Externado Colombia, 2004; L. CLÉRICO. El examen de proporcionalidad en el derecho constitucional. Buenos Aires: Universitaria de Buenos Aires, 2009; L. Clérico, J. R. Sieckmann y D. Oliver-Lalana. Prólogo. En L. CLÉRICO, coord. Derechos fundamentales, principios y argumentación: Estudios sobre la teoría jurídica de Robert Alexy. Granada: Comares, 2011, vII-VIII.

108 Dworkin, R. Hard Cases. Harvard Law Review. 1975, 88(6), 1057-1109.

109 Sin embargo, existen dudas sobre si la reconstrucción racionalista de ALEXY es capaz de concebir analíticamente y guiar normativamente las decisiones judiciales de manera convincente, es decir, si el derecho y la política son tan fáciles de distinguir como sostiene. Quizás sea el racionalismo extremo el atractivo de la teoría para la región. 
A pesar de la incertidumbre que el nuevo rol de los tribunales genera, existe consenso en el sentido de que el aumento de poder de los órganos jurisdiccionales debe ser acompañado con políticas adecuadas. Por ejemplo, desde el reconocimiento de la doctrina del control de convencionalidad, México emprendió enérgicamente un programa de capacitación de jueces ${ }^{110}$. Pero el acompañamiento del cual se habla aquí requiere también de la atención del público en general ${ }^{111}$, de una reforma en la formación de los profesionales en derecho ${ }^{112}$, así como de una academia crítica pero al mismo tiempo constructiva $^{113}$, el tipo de academia con la cual se identifican los representantes del Ius Constitutionale Commune. En este contexto, el sistema jurídico puede dar un aporte importante y específico al proceso de transformación, aunque claramente no puede sustituir un proceso político en el sentido amplio.

\section{Sobre el rol de las instituciones regionales}

Otro rasgo particular del Ius Constitutionale Commune frente a otros proyectos transformadores más antiguos es la superación del horizonte estrictamente estatal: interrelaciona el derecho constitucional y el derecho internacional público y les atribuye a las instituciones internacionales una medida importante de autonomía. El alcance de este desarrollo se manifiesta en la concepción imperante sobre la soberanía. Este concepto ha sido trascendental en Latinoamérica, al menos desde el momento de la doctrina $\mathrm{CALVO}^{114}$. Según dicha concepción tradicional, funciona como "escudo" para proteger la soberanía interna, y en general concibe al ordenamiento jurídico de los Estados latinoamericanos como un tipo de "universo normativo", no obstante las numerosas instancias de "inspiración” jurídica provenientes de países vecinos, o bien de Europa o Norteamérica. Las dimensiones cuasi-continentales de algunos

110 Corte Interamericana de Derechos Humanos, Resolución de 14 de mayo 2013, Radilla Pacheco vs. México, Supervisión de cumplimiento de sentencia. Del punto 37 en adelante la Corte valora positivamente los programas de capacitación de los jueces.

111 Las sesiones de algunos tribunales supremos pueden ser vistas en televisión, e incluso se transmiten sus deliberaciones "internas". La utilidad de la transmisión para fomentar un público crítico es un punto de controversia: cfr. C. HüBner Mendes. Constitutional Courts and Deliberative Democracy. Oxford: oup, 2013, 164-166.

112 De la Garza, en Rasgos, ob. cit. 21, 216.

113 H. FIX-FIERRo. Los juristas académicos del Instituto de Investigaciones Jurídicas de la UNAM y la construcción de las nuevas instituciones democráticas. En H. VÁZQUEZ RAMOs, coords. Cátedra Nacional de Derecho Jorge Carpizo. Reflexiones Constitucionales. México D.F.: UnAM, 2014, 451-459.

114 C. Calvo. Derecho internacional teórico y práctico de Europa y América. Vol. 1. Paris: D' Amyot, 1868, en particular 301-302; F. TAMBURINI. Historia y destino de la "doctrina calvo": ¿actualidad u obsolescencia del pensamiento de Carlos Calvo? Revista de Estudios HistóricoJurídicos. 2012, 24, 81-101; sobre las implicaciones para el Estado: J. M. SERNA DE LA GARZA. Impacto e implicaciones constitucionales de la globalización en el sistema jurídico mexicano. México D.F.: unAm, 2012, 9 ss. 
Estados (en especial Brasil, pero también México y Argentina), así como las fórmulas económicas de los años sesenta y setenta del siglo xx que insistían en un desacoplamiento del mercado mundial, reforzaron esta concepción tradicional de la soberanía ${ }^{115}$.

Ahora bien, hoy en día, la famosa premisa del concepto clásico de soberanía, aquella que sostiene que los Estados constituyen "comunidades independientes" 116 , ha sido modificada por la globalización, inclusive en los países de dimensión cuasi-continental. Tomando el ejemplo del ordenamiento jurídico mexicano, Héctor Fix Fierro y José María Serna han mostrado que estos cambios también han surtido efectos profundos en Latinoamérica ${ }^{117}$. Pero no es la comprensión del aspecto jurídico de la globalización lo que impele a los representantes del Ius Constitutionale Commune a reconfigurar el concepto tradicional de soberanía. Todo lo contrario: el escepticismo frente a las organismos económicos internacionales, como el Banco Mundial, el Fondo Monetario Internacional o bien los tribunales arbitrales en materia de inversión, es mucho más profundo que en Europa ${ }^{118}$. En general se asocian con el "Consenso de Washington" de los años noventa, de corte "neoliberal", el cual dejó una huella profunda y hasta hoy palpable, ya que según muchos autores recrudeció sustancialmente el problema de la exclusión ${ }^{119}$. En Latinoamérica se es mucho más consciente que en Europa de que muchos tratados e instituciones internacionales tienen un sesgo en beneficio del "Norte global".

Así pues, los representantes del ICCAL no abogan por una apertura general sino más bien por la salvaguarda específica de los derechos humanos, la democracia y el Estado de derecho. La relevancia del principio de soberanía no se pone en tela de juicio. Pero esto no quiere decir que no sufra una transformación, porque en su nueva concepción pasa de ser una figura de cierre a convertirse en un principio funcional que se pone al servicio de los principios

115 Influyente R. PreBisch. Hacia una dinámica del desarrollo latinoamericano. México D.F.: FCE, 1961, en particular 89-94

116 Formulado en estos términos por la Corte Permanente de Justicia Internacional, Sentencia de 7 de noviembre de 1927, S.S. Lotus, Francia vs. Turquía, Serie A, n. ${ }^{\circ} 10$ (1927), 18.

117 H. Fix-Fierro y S. LÓPEZ-AyLLón. The Impact of Globalization on the Reform of the State and the Law in Latin America. Traducido por Virginia Davis. Houston Journal of International Law. 1996-1997, 19, 785-805, en particular 795; SERNA DE LA GARZA, en Impacto, ob. cit. 30, pp. 111 ss.

118 En relación con las instituciones de Bretton Woods, A. Girón, A. Financiamiento del desarrollo. Endeudamiento externo y reformas financieras. En G. VIDAL y R. A. GuILLÉn, coords. Repensar la teoría del desarrollo en un contexto de Globalización. Homenaje a Celso Furtado. Buenos Aires: CLASCO, 2007, 125-142. Sobre los tratados internacionales de comercio: R. RoJAS. El TLC: Poder y representación en el capitalismo contemporáneo. Colombia Internacional. 2005, 61,116-133; C. AhumadA. Comercio, género y propiedad intelectual: TLC entre Estados Unidos y Colombia. En A. GIRón, coord. Género y Globalización. Buenos Aires: CLASCO, 2009, 165-187.

119 Enfático en este sentido Gargarella, ob. cit. 9, 151 ss. 
fundamentales. Las instituciones del derecho internacional se entienden así como conquistas del derecho constitucional ${ }^{120}$.

El nombre de una conferencia que se celebró con ocasión del bicentenario de la Revolución de Mayo de 1810 en Argentina captó de manera muy atinada la idea principal del constitucionalismo actual de la región: internacionalización del derecho constitucional, constitucionalización del derecho internacional ${ }^{121}$. Claro está que la internacionalización del derecho constitucional y la constitucionalización del derecho internacional son fenómenos bien conocidos en Europa ${ }^{122}$. No obstante, la dinámica de transformación latinoamericana no es un mero ejemplo adicional de cómo funcionan estos fenómenos, sino que goza de destacada originalidad y fuerza innovadora.

A nivel estatal, las novedades dignas de mencionar son bien captadas con el concepto de estatalidad abierta de KLAus VogeL ${ }^{123}$. No obstante, la apertura en Latinoamérica es distinta a la de Alemania. La seguridad colectiva y la integración no juegan el mismo papel central. Los países latinoamericanos, tras el regreso a la democracia, han decidido más bien abrirse a las normas internacionales de protección de los derechos humanos para así proteger mejor los principios fundamentales de sus propias constituciones ${ }^{124}$. Se puede hablar de una estatalidad abierta doble, ya que los tratados de derechos humanos gozan de otro tipo de incorporación que los tratados de integración económica ${ }^{125}$.

La primacía del derecho internacional público, como bien lo expresó el ilustre constitucionalista mexicano y precursor del Ius Constitutionale Commune, Héctor Fix-Zamudio, solo aplica con respecto a los tratados

120 M. Morales Antoniazzi. Protección supranacional de la democracia en Suramérica. Un estudio sobre el acervo del ius constitutionale commune. México D.F.: unAM, 2014 (en prensa). Sikkink muestra además que los juristas y políticos de antaño no tenían la intención de usar el principio de soberanía para escudarse de los reclamos sobre violaciones de derechos humanos: K. SIKKINK. Reconceptualizing Sovereignty in the Americas: Historical Precursors and Current Practices. Houston Journal of International Law. 1996-1997, 19, 705-729 (712).

121 El libro producto de la conferencia fue coordinado por G. CAPALDO, J. SieKmann y L. ClérICo. Internacionalización del derecho constitucional, constitucionalización del derecho internacional. Buenos Aires: Eudeba, 2012; sobre el tema, en general, H. FiX-ZAmUdIo. La creciente internacionalización de las Constituciones iberoamericanas, especialmente en la regulación y protección de los derechos humanos. En La Justicia Constitucional y su Internacionalización, ob. cit. 11, 583-673.

122 Cfr. H. RuIz FABRi y M. Rosenfeld, coords. Repenser le constitutionnalisme à l'âge de la mondialisation et de la privatisation. Paris: Société de législation comparée, 2011.

123 K. Vogel. Die Verfassungsentscheidung des Grundgesetzes für die internationale Zusammenarbeit. Tübingen: Mohr, 1964.

124 En este sentido se observan paralelismos con las constituciones post-socialistas de Europa central y del este; en detalle, M. Hofmann. Von der Transformation zur Kooperationsoffenheit? Die Öffnung der Rechtsordnungen ausgewählter Staaten Mittel- und Osteuropas für das Völker- und Europarecht. Berlín/Heidelberg: Springer, 2009.

125 De manera extensa, Morales AntoniazZI, ob. cit. 122. 
internacionales de derechos humanos ${ }^{126}$. Un ejemplo emblemático es la Constitución de Colombia de 1991 que, entre otras varias disposiciones, establece que "los tratados y convenciones internacionales ratificados por el Congreso prevalecen en el orden interno" y, a la vez, dispone que todos los derechos fundamentales constitucionales deben ser interpretados a la luz de los tratados internacionales ratificados por Colombia (art. 93). Esta norma ha dado lugar a la distinción entre bloque de constitucionalidad strictu y lato sensu. Otra constitución ejemplar es la de Argentina de 1994, que en su artículo 75 , inciso $22^{[127]}$, incorpora una lista extensa de tratados de derechos humanos al orden constitucional argentino. Esta disposición constitucional plasma la política en materia de derechos humanos y justicia de transición que Argentina persiguió tras la dictadura ${ }^{128}$, la piedra angular de una jurisprudencia transformadora que bajo el nombre "justicia de transición" logró convertirse en una figura jurídica de carácter global ${ }^{129}$. La Constitución de Ecuador de 2008 regula, por una parte, que "los derechos y garantías establecidos en la Constitución y en los instrumentos internacionales de derechos humanos serán de directa e inmediata aplicación por y ante cualquier servidora o servidor público, administrativo o judicial, de oficio o a petición de parte" (art. 11.3), y por otra parte establece que "en el caso de los tratados y otros instrumentos internacionales de derechos humanos se aplicarán los principios pro ser humano, no restricción de derechos, de aplicabilidad directa

126 H. Fix-ZAmudio. El derecho internacional de los derechos humanos en las Constituciones latinoamericanas y en la Corte Interamericana de Derechos Humanos. Revista Latinoamericana de Derecho. 2004, 1, 141-180, en particular 147-151; sobre sus obras C. GAVIRIA TruJILlo. Presentación. Honores y Justicia al Juez Fix-Zamudio. En Liber amicorum Héctor Fix-Zamudio. Vol. 1. San José: Secretaría de la Corte Interamericana de Derechos Humanos, 1998, XLIX-LII; E. Ferrer Mac-Gregor. Semblanza del Maestro Héctor Fix-Zamudio. En E. Ferrer MaC-Gregor y A. ZALDÍVAR LELO DE LARREA, coords. La ciencia del derecho procesal constitucional. Estudios en homenaje a Héctor Fix-Zamudio en sus cincuenta años como investigador del derecho. México D.F.: unAm, 2008, xxxv-XL; G. de Vergottini, Premessa. En L. Mezzetti y E. Ferrer MAC-GRegor, coords. Diritto processuale costituzionale. Omaggio italiano a Héctor Fix-Zamudio per $i$ suoi 50 anni di ricercatore di diritto. Milán: CEDAM, 2010, 3-5.

127 El artículo 75, inciso 22, de la Constitución argentina menciona los siguientes tratados: la Declaración Americana de los Derechos y Deberes del Hombre; la Declaración Universal de Derechos Humanos; la Convención Americana sobre Derechos Humanos; el Pacto Internacional de Derechos Económicos, Sociales y Culturales; el Pacto Internacional de Derechos Civiles y Políticos y su Protocolo Facultativo; la Convención sobre la Prevención y la Sanción del Delito de Genocidio; la Convención Internacional sobre la Eliminación de todas las Formas de Discriminación Racial; la Convención sobre la Eliminación de todas las Formas de Discriminación contra la Mujer; la Convención contra la Tortura y otros Tratos o Penas Crueles, Inhumanos o Degradantes; la Convención sobre los Derechos del Niño.

128 J. S. Elias. Constitutional Changes, Transitional Justice and Legitimacy: The Life and Death of Argentina's “Amnesty Laws", Student Scholarship Papers. Paper 57, disponible en: [http://digitalcommons.law.yale.edu/student_papers/57]

129 Fundamental, R. TeItel. Transitional Justice. Oxford: oup, 2000; R. Teitel. Transitional Justice Genealogy. Harvard Human Rights Journal. 2003, 16, 69-94. 
y de cláusula abierta establecidos en la Constitución" (art. 417). Dispone igualmente que "la Constitución y los tratados internacionales de derechos humanos ratificados por el Estado que reconozcan derechos más favorables a los contenidos en la Constitución, prevalecerán sobre cualquier otra norma jurídica o acto del poder público" (art. 424).

Otro ejemplo importante es, desde junio de 2011, una referencia a los tratados internacionales ratificados en materia de derechos humanos en el artículo 1 , inciso $1 .^{\circ}$, de la Constitución mexicana, en donde se les reconoce rango constitucional. Solo un mes después, el más alto tribunal mexicano ya había confirmado y aplicado esta disposición ${ }^{130}$. Inclusive las constituciones marcadas por el constitucionalismo bolivariano les atribuyen un papel importante a los derechos humanos. La Constitución boliviana de 2009 dispone que las garantías internacionales en materia de derechos humanos tienen un rango superior al derecho interno, y que los derechos y deberes de la Constitución deben ser interpretados de conformidad con el derecho internacional ${ }^{131}$. Además, las normas convencionales tienen un rango superior a la Constitución en la medida en que otorguen mayores derechos ${ }^{132}$. En otros Estados se han producido estos mismos cambios por medio de la interpretación constitucional. Por ejemplo, desde 1995, la Sala Constitucional de Costa Rica les atribuye rango supraconstitucional a los tratados de derechos humanos en la medida en que otorguen mayores derechos o garantías a las personas ${ }^{133}$.

La apertura de la estatalidad opera doctrinariamente con la figura jurídica del bloque de constitucionalidad, una figura importada de Europa pero ingeniosamente adaptada a la realidad latinoamericana ${ }^{134}$. El Consejo Constitucional francés fue quien la desarrolló para crear una jurisdicción constitucional a partir de la Declaración francesa de los Derechos del Hombre y del Ciudadano y del catálogo de derechos fundamentales de la Constitución de la Cuarta República. El Tribunal Constitucional de España modificó esta figura y a través de la misma incorporó la legislación ordinaria sobre la organización territorial española al derecho constitucional. Así, reconoció el valor superior de los Estatutos de Autonomía, lo cual fomentó un mayor equilibrio entre el

130 Suprema Corte de Justicia de la Nación (México), Decisión en el asunto "Varios 912/2010", de 14 de julio de 2011; al respecto E. FERRER MAC-GrEGOR. Hacia la formación jurisprudencial interamericana de un Ius Constitutionale Commune Americanum. Eficacia de la sentencia interamericana y la cosa juzgada internacional (sobre el cumplimiento del caso Gelman vs. Uruguay). En Rasgos, ob. cit. 21,329, 347 ss.

131 Art. 13.Iv de la Constitución boliviana.

132 Art. 256 de la Constitución boliviana.

133 Sala Constitucional de la Corte Suprema de Costa Rica, Voto 2313-95 de las 16:18 horas del 9 de mayo de 1995.

134 M. GóngOra MERA. La difusión del bloque de constitucionalidad en la jurisprudencia latinoamericana y su potencial en la construcción del ius constitutionale commune latinoamericano. En Rasgos, ob. cit. 21, 301. 
Estado central y las comunidades. Se ve entonces que mientras en Francia y España la figura se utiliza para incorporar normas del derecho estatal al derecho constitucional, en Latinoamérica el bloque de constitucionalidad se utiliza para integrar normas de derecho internacional al ordenamiento jurídico estatal, lo cual fortalece argumentativamente a los tribunales que apoyan una transformación democrática.

Los elementos provenientes del derecho internacional público que conforman el bloque constitucional, tal y como lo ilustra el listado de la Constitución argentina, son muy variados. El estado de ratificación de los tratados internacionales es heterogéneo en la región, lo cual evidencia que el Ius Constitutionale Commune no es un fenómeno uniforme ${ }^{135}$. Sin embargo, sigue estando conformado por un núcleo común: el sistema interamericano de protección de los derechos humanos, sobre todo gracias a la labor de sus instituciones. Su importancia para la región justifica que se hable de interamericanización de manera similar a como se habla de europeización ${ }^{136}$.

El hecho de que el sistema interamericano se haya convertido en el núcleo normativo del Ius Commune no se debe a ninguna característica inherente al mismo; se debe mucho más al respaldo que las fuerzas transformadoras en los varios países encontraron en él para sus proyectos en el contexto nacional ${ }^{137}$. La función principal del plano internacional consiste entonces en inclinar la balanza del poder en el plano estatal interno a favor de los proyectos constitucionales con vocación transformadora ${ }^{138}$. La denuncia de Venezuela de la Convención, la cual se anunció en septiembre de 2012 y surtió efecto un año después, es una señal de la autoridad de la Corte; el mero incumplimiento de las decisiones interamericanas dejó de ser una opción viable para el gobierno venezolano.

A su vez, la Corte, en los 173 casos decididos, ha desarrollado una jurisprudencia a la medida de la problemática de la región ${ }^{139}$. No ha titubeado en anular leyes de amnistía ${ }^{140}$, en dar efectos directos y erga omnes a sus deci-

135 Morales AntoniazZi, ob. cit. 122.

136 Sentando las bases de estas idea Morales AntoniazZI, ob. cit. 122.

137 Parra Vera, en Rasgos, ob. cit. 21, 383 ss.

138 El cumplimiento de este objetivo depende de la composición de la Comisión y la Corte; en última instancia, nada puede impedir que la Corte persiga objetivos distintos cuando su composición varíe; pensemos, por ejemplo, en las diferencias tan palpables de la Corte Suprema de Estados Unidos de Warren en contraste con la de Renquist; al respecto, D. P. CURRIE. The Constitution in the Supreme Court: The Second Century 1888-1986. Chicago/Londres: University of Chicago Press, 1990, 599-601.

139 Expuesta de manera sistemática por L. Burgorgue-Larsen y A. Úbeda de Torres. The Inter-American Court of Human Rights. Case Law and Commentary. Traducido por Rosalind Greenstein. Oxford: oup, 2011; J. Кокотт. Das interamerikanische System zum Schutz der Menschenrechte. Berlin/Heidelberg: Springer, 1986.

140 C. BINDER. Auf dem Weg zum lateinamerikanischen Verfassungsgericht? Die Recht- 
siones ${ }^{141}$ ni en ordenar medidas específicas ${ }^{142}$. Estas sentencias han desatado una dinámica que ha dado impulso al Ius Constitutionale Commune, creando lo que la misma CorteidH llama el corpus iuris ${ }^{143}$. Este corpus iuris así como los efectos tan marcados de su jurisprudencia han despertado el debate sobre la legitimidad de sus actos y su legitimidad como institución. Esta crítica no proviene únicamente de instituciones que hayan sido el blanco de sus acciones ${ }^{144}$ sino también de autores que en principio apoyan la creatividad y la orientación de su jurisprudencia ${ }^{145}$. Parece ser que la Corte se ha percatado del problema, y la decisión de celebrar "sesiones itinerantes" en los distintos Estados que hubieran aceptado la competencia contenciosa podría considerarse una reacción en este sentido ${ }^{146}$. Las sesiones itinerantes tienen como propósito acercar a la Corte a los Estados parte y a los interesados. El diálogo constante con organizaciones de la sociedad civil también es característico

sprechung des Interamerikanischen Menschenrechtsgerichtshofs im Bereich der Amnestien. ZaöRV. 2011, 71, 1-29.

141 Enfático al respecto A. CASSESE. Y a-t-il un conflit insurmontable entre souveraineté des États et justice pénale internationale? En M. CASSESE y M. Delmas-Marty, coords. Crimes internationaux et juridictions internationales. París: Presses Universitaires de France, 2002, 13-29, 16; M. Góngora Mera. Inter-American Judicial Constitutionalism. On the Constitutional Rank of Human Rights Treaties in Latin America through National and Inter-American Adjudication. San José: Inter-American Institute for Human Rights, 2011, 54. Esto aplica sobre todo respecto de las violaciones más graves de derechos humanos, tales como la tortura o las ejecuciones extrajudiciales, las cuales representan una violación al jus cogens según la Corte. Véase BINDER, ob. cit. 142, 13.

142 Competencia prevista de manera expresa en el artículo 63.1.2 de la Convención Americana sobre Derechos Humanos. Las medidas ordenadas incluyen la difusión del reconocimiento de responsabilidad por parte del Estado, la construcción de monumentos en memoria de las víctimas, así como la adopción de reformas legislativas, todas estas con el objetivo de remediar las violaciones ocurridas y prevenir nuevas violaciones. Cfr. BURGORGUE-LARSEN y ÚBEDA DE TORRES, ob. cit. 141, 234-238, con referencias adicionales.

143 Opinión Consultiva OC-16/99, solicitada por los Estados Unidos Mexicanos, sobre "El derecho a la información sobre la asistencia consular en el marco de las garantías del debido proceso legal", párr. 115; cfr. también S. García Ramírez, Foreword. En Burgorgue-Larsen y ÚBEDA DE TORRES, ob. cit. 141, xvii-xxviii, en particular xx.

144 Compárese sobre todo con la Corte Suprema venezolana que sostiene la "inaplicabilidad" de las sentencias de la Corte Interamericana de Derechos Humanos en razón de "usurpación de funciones": véase Corte Suprema, Sala Constitucional, exp. 08-1572. Sentencia de 18 de diciembre de 2008, disponible en: http://www.tsj.gov.ve/decisiones/scon/ diciembre/1939-181208-2008-08-1572.html Al respecto C. Ayala Corao. La doctrina de la "inejecución" de las sentencias internacionales en la jurisprudencia constitucional de Venezuela (1999-2009). En La Justicia Constitucional y su internacionalización, ob. cit. 11, 85 ss.

145 Gargarella, ob. cit. 9, 170 ss.

146 P. SaAvedra Alessandri y G. Pacheco Arias. Las sesiones "itinerantes" de la Corte Interamericana de Derechos Humanos: un largo y fecundo caminar por América. En S. García Ramírez y M. Castañeda Hernández, coords. Recepción nacional del derecho internacional de los derechos humanos y admisión de la competencia contenciosa de la Corte Interamericana. México: UnAm, 2009, 37. 
del sistema ${ }^{147}$. Por último, la Corte ha contribuido a la consolidación de la democracia en América Latin ${ }^{148}$. A pesar de todo, la respuesta a las críticas sobre legitimidad sigue siendo un tema inacabado ${ }^{149}$.

El sistema interamericano de protección de los derechos humanos es el mecanismo regional más importante para afianzar el constitucionalismo pero no el único. La Carta Democrática Interamericana es otro de estos mecanis$\operatorname{mos}^{150}$. Se trata de una resolución de la Organización de Estados Americanos sin carácter vinculante pero que contiene un mecanismo de control que ya se utilizó en el pasado para la promoción de la democracia ${ }^{151}$.

Otro mecanismo que también tiene como objeto la consolidación del constitucionalismo lo encontramos en el Mercosur ${ }^{152}$. Si bien la integración económica es el enfoque primordial de este régimen, ha dirigido su atención también hacia cuestiones de carácter constitucional. El Protocolo de Asunción incorpora la protección de los derechos humanos y el Protocolo de Ushuaia promueve la protección de la democracia por medio de un proceso político. Claro está, ningún protocolo asegura por sí mismo el constitucionalismo. Eso lo muestra claramente el caso paraguayo de 2012, el cual sirvió como estrategia para eludir la resistencia de Paraguay a aceptar a Venezuela como miembro del Mercosur ${ }^{153}$.

Con bastante frecuencia, las instituciones internacionales que he mencionado son denominadas supranacionales ${ }^{154}$. Claro está que el entendimiento que se tiene de la supranacionalidad no es el mismo que impera en Europa, el cual está íntimamente relacionado con la Unión Europea. La utilización latinoamericana del término es más flexible, ya que aborda de manera mucho más abstracta la cuestión de la superación de la concepción contractualista

147 Piovesan, en Rasgos, ob. cit. 21, 75.

148 O. PARRA. Lucha contra la impunidad, independencia judicial y derechos de los pueblos indígenas. Algunos avances y debates en torno a la jurisprudencia de la Corte Interamericana de Derechos Humanos. En F. Rey Martínez, coord. Los derechos en Latinoamérica: tendencias judiciales recientes. Madrid: Complutense, 2012,363-416. Sobre el nuevo rol de los Tribunales: S. CASSESE. I Tribunali di Babele. I giudici alla ricerca di un nuovo ordine globale. Roma: Donzelli, 2009.

149 A. v. Bogdandy e I. VenzKe. In whose Name? A Public Law Theory of Adjudication. Oxford: Oxford University Press, 2014.

150 En detalle, Morales Antoniazzi, ob. cit. 122.

151 J. M. CASAL HeRnÁndez. Las restricciones al ejercicio de los derechos humanos y la cláusula de la sociedad democrática en el sistema interamericano. En A. SAIz Arnaiz, M. Morales ANTONIAZZI y J. UGARTEMENDIA, coords. Las implicaciones constitucionales de los procesos de integración. Oñate: Instituto Vasco de Administración Pública, 2011, 477-505.

152 En detalle Morales Antoniazzi, ob. cit. 122.

153 Malamud, en Rasgos, ob. cit., 117 ss.

154 V. BAZÁn. La integración supranacional y el federalismo en interacción: perspectivas y desafíos. Anuario de Derecho Constitucional Latinoamericano. 2009, 15, 639-687. J. L. CAVALLARO y E. J. SchafFER. "Less as More: Rethinking Supranational Litigation of Economic and Social Rights in the Americas", Hastings Law Journal. 2004, 56(2), 217-282. 
y horizontal del derecho internacional. Por esta razón muestra un potencial generalizador mayor.

\section{Pluralismo dialógico}

La tríada de los derechos humanos, la democracia y el Estado de derecho denota, de manera muy abstracta, el objetivo constitucional a cuyo servicio deberían estar los tribunales y las instituciones internacionales: la institucionalidad. Pluralismo dialógico, el último concepto que aquí se define, tiene dos acepciones en el Ius Constitutionale Commune: es a la vez un objetivo del ICCAL así como un medio para alcanzarlo. Designa una modalidad de interacción social y para la resolución de conflictos que al mismo tiempo supone la situación social a la cual aspira. Al igual que los otros conceptos que aquí se han definido, el pluralismo dialógico está anclado en el discurso universal; presenta, eso sí, características muy latinoamericanas.

Normalmente se describen tres fenómenos distintos con el pluralismo ${ }^{155}$. En el derecho constitucional es un concepto antiguo que denota una sociedad en donde los distintos grupos que la conforman, se enfrentan los unos con los otros en procesos públicos y democráticos con respecto a una amplia gama de valores, intereses y formas de vida. En segundo lugar, se refiere a normas que no forman parte del ordenamiento jurídico estatal pero que rigen las relaciones sociales de ciertos grupos ${ }^{156}$. El tercer fenómeno se refiere a la interacción entre los distintos regímenes jurídicos, en especial a la relación abierta entre el derecho constitucional estatal, el derecho de la Unión Europea y el derecho europeo en materia de derechos humanos ${ }^{157}$.

Los tres aspectos y fenómenos los podemos encontrar en el Ius Constitutionale Commune en América Latina, empero, la interacción es mucho más marcada en la región. De nuevo, la exclusión es el factor más importante para explicar esta particularidad. Para construir una sociedad verdaderamente pluralista en la región es indispensable procurar la inclusión de la población indígena y afrodescendiente, es decir, darles espacio en las instituciones estatales y reconocer que son grupos con valores e intereses específicos. Esto implica también el segundo aspecto del pluralismo, ya que a menudo estos

155 T. IsIKSEL. Global Legal Pluralism as Fact and Norm. Global Constitutionalism. 2013, 2, $160 \mathrm{ss}$.

156 F. v. Benda-Beckmann. Who's Afraid of Legal Pluralism? J. Legal Pluralism \& Unofficial L. 2002, 47, 37-82, en particular 60-62; un ejemplo en Europa son los grupos musulmanes, FoBlets, M. Diversité Religieuse en Europe: Une Approche Innovante Conjuguant l'Approche Juridique et Sociologique. En Ast, F. y Duarte, B., coords. Les Discriminations Religieuses en Europe: Droit et Pratiques. Paris: L'Harmattan, 2012, 105-119.

157 N. WALKER. The Idea of Constitutional Pluralism. Modern Law Review. 2002, 65, 317; Wendel, M. Permeabilität im europäischen Verfassungsrecht.Verfassungsrechtliche Integrationsnormen auf Staats- und Unionsebene im Vergleich. Tübingen: Mohr Siebeck, 2011. 
grupos cuentan con un orden normativo propio y particular. La inclusión real exige una participación que comprenda sus órdenes normativos. Aquí encontramos algunas innovaciones constitucionales recientes muy importantes. Desde 2001 y como reacción al levantamiento zapatista en Chiapas, la Constitución mexicana dispone en su artículo 2 que la Nación mexicana es pluricultural y por ende también incluye a los pueblos indígenas como tales. La Constitución boliviana de 2009 es la más avanzada en este sentido ya que también integra principios éticos de los pueblos indígenas ${ }^{158}$, así como la cosmología indígena y ciertas formas de propiedad colectiva ${ }^{159}$. En el Ius Constitutionale Commune dichas disposiciones no son vistas como mero folclor. Es más, se reconoce el potencial que en ellas se encierra y por esta razón son objeto de análisis teórico ${ }^{160}$. Pero hay que reconocer que es un desafío enorme incorporar de manera orgánica los principios de los pueblos precolombinos a los Estados constitucionales modernos. Para el elemento común del Ius Constitutionale Commune queda también claro que debe dejar mucho espacio a la diversidad, respondiendo así a las numerosísimas y diversísimas formas del tejido social y cultural de los pueblos latinoamericanos.

La jurisprudencia de la Corte Interamericana depende, primero, del pluralismo social, ya que muchas de sus sentencias paradigmáticas son el fruto del litigio estratégico de agrupaciones de la sociedad civil ${ }^{161}$. Segundo, sus sentencias habitualmente apoyan al pluralismo social o al pluralismo étnicocultural. Tercero, la firmeza con la cual actúa respecto a situaciones internas ha hecho de su relación con los tribunales nacionales un tema clave. También aquí el concepto de pluralismo es sumamente importante.

La figura central de esta discusión se denomina control de convencionalidad y representa el núcleo doctrinal del Ius Constitutionale Commune. Esta figura fue creada por la Corte en el caso Almonacid Arellano vs. Chile ${ }^{162}$. Exige a los tribunales nacionales la aplicación de la Convención Americana de conformidad con la interpretación que la Corte haya hecho de la misma. Según esta decisión, cuyo alcance exacto todavía se desconoce, todos los

158 Compárese con el artículo 8: "El Estado asume y promueve como principios éticomorales de la sociedad plural: ama qhilla, ama llulla, ama suwa (no seas flojo, no seas mentiroso ni seas ladrón), suma qamaña (vivir bien), ñandereko (vida armoniosa), teko kavi (vida buena), ivi maraei (tierra sin mal) y qhapaj ñan (camino o vida noble)".

159 R. Prada Alcoreza. Análisis de la nueva Constitución Política del Estado. Crítica y emancipación. Revista Latinoamericana de Ciencias Sociales. 2008, 1, 35-50 (48-50).

160 Clérico y Aldao, en Rasgos, ob. cit. 21,220; Morales Antoniazzi, en Rasgos, ob. cit. $21,266$.

161 Piovesan, en Rasgos, ob. cit. 21, 72 ss.

162 Corte Interamericana de Derechos Humanos, Almonacid Arellano vs. Chile; Sentencia de 26 de setiembre de 2006, Serie C, n. ${ }^{\circ}$ 154, párr. 124; SAGÜÉs, ob . cit. 7, 117; GARCía RAMírez, ob. cit. 7, 123; H. Nogueira Alcalá. Diálogo interjurisdiccional, control de convencionalidad y jurisprudencia del Tribunal Constitucional en período 2006-2011. Estudios Constitucionales. 2012, 10(2), 57. 
actos estatales quedan sujetos al control de su conformidad con la Convención, y en caso de conflicto con la misma no pueden ser aplicados por los tribunales nacionales. Esto produce efectos sustanciales en la distribución de competencias a nivel estatal: tanto en la relación del poder judicial con los otros poderes como en la jerarquía en el seno del poder judicial. En particular ha afectado el papel de los tribunales supremos. Considerando que además la Corte Interamericana le atribuye aplicación directa y efectos erga omnes a su jurisprudencia ${ }^{163}$, que ha declarado la inaplicabilidad de leyes nacionales, decretado que se emprendan reformas legislativas y ordenado una amplia gama de medidas concretas, se ha generado una dinámica impresionante ${ }^{164}$. La dimensión constitucional es evidente ${ }^{165}$, en especial debido a que los temas tratados son altamente políticos, temas sobre los cuales ciertos grupos sociales se encuentran en profundo desacuerdo. No sorprende entonces que la jurisprudencia interamericana haya suscitado un rico debate. El desafío consiste en acomodar cuidadosamente la dinámica transformadora con el entramado institucional y la distribución de competencias a nivel estatal. Aquí encuentra aplicación la tercera definición del concepto de pluralismo ${ }^{166}$, si bien otros conceptos compiten por describir la situación, como por ejemplo: redes de colaboración horizontal ${ }^{167}$, trapecio ${ }^{168}$, redes constitucionales ${ }^{169}$, normativismo supranacional ${ }^{170}$, transconstitucionalismo ${ }^{171}$.

163 Descrito detalladamente por Eduardo Ferrer Mac-Gregor en el sensible caso Gelman, en el cual la Corte declara sin efectos una ley de amnistía con credenciales democráticas impecables y la declaró "sin efectos": Rasgos, ob. cit. 21,329 ss.; R. GARGARELLA. Sin lugar para la soberanía popular. Democracia, derechos y castigo en el caso Gelman. Seminario de Latinoamérica de Teoría Constitucional y Política de la Universidad de Yale (online), 2013. Disponible en: http://www.law.yale.edu/documents/pdf/sela/SELA13_Gargarella_CV_Sp_20120924.pdf; T. Rincón-CovelLI. El derecho internacional de los derechos humanos: ¿límite o elemento constitutivo de la democracia? A propósito de la transición uruguaya a la democracia. Estudios Socio-Jurídicos. 2012, 14(2), 71-106; P. SFERRAZZA TAIBI. ¿Amnistías democráticas? El Caso Gelman vs. Uruguay de la Corte Interamericana de Derechos Humanos: un caso práctico para una reflexión teórica. En S. A. Santano y S. A. Mejías, coords. La seguridad, un concepto amplio y dinámico: v Jornadas de estudios de seguridad. Madrid: IUGM-UNED, 2013, 323-356.

164 Una decisión pionera en este sentido es Corte Interamericana de Derecho Humanos, Barrios Altos (Chumbipuma Aguirre y otros vs.Perú), Sentencia de 14 de marzo de 2001, Fondo, Serie C, n. ${ }^{\circ} 75$.

165 Expuesto sutilmente por Burgorgue-Larsen, L. La Corte Interamericana de Derechos Humanos como tribunal constitucional. En Rasgos, ob. cit. 21, 421.

166 De LA GARZA. en: Impacto, ob. cit. 116, 243 ss.

167 J. P. PAmpillo B AliÑo. The Legal Integration of the American Continent: An Invitation to Legal Science to Build a New Ius Commune. ILSA Journal of International \& Comparative Law. 2011, 17(3), 517-533 (519).

168 Piovesan, ob. cit. 7, 67.

169 R. Bustos Gisbert. Pluralismo constitucional y diálogo jurisprudencial. México: Porrúa, 2012, 13 ss.

170 A. Gordillo et al. Derechos Humanos. Vol. 5. Buenos Aires: Fundación de Derecho Administrativo, 2005, p. 10, con referencias adicionales.

171 Neves, ob. cit. 64, 115 ss. 
Las perspectivas pluralistas se dividen en dos campos. La posición más radical parte de la visión de que los conflictos que se ocasionan son conflictos de poder y que por ende difícilmente pueden ser abordados desde el razonamiento jurídico ${ }^{172}$. La posición del diálogo tiene un punto de partida diametralmente opuesto: la observación de que los diversos regímenes jurídicos e instituciones normalmente desarrollan relaciones jurídicas estables no obstante su independencia normativa. Esta posición sostiene que los conflictos fundamentales son una gran excepción: la regla consiste más bien en un trabajo conjunto y fructífero ${ }^{173}$. Los representantes del Ius Constitutionale Commune optan por el pluralismo dialógico y así reconstruyen la interacción entre la Corte Interamericana y los tribunales nacionales ${ }^{174}$.

\section{RESUMEN}

El Ius Constitutionale Commune en América Latina representa un enfoque transformador que se dota de energía a partir de la experiencia concreta y la convicción profunda de la inaceptabilidad de situaciones de injusticia sistemática. Su sustrato de derecho positivo lo constituyen principalmente la Convención Americana sobre Derechos Humanos, las garantías de las constituciones nacionales sobre la misma materia, las cláusulas de apertura, así como la correspondiente jurisprudencia, tanto nacional como internacional. Apuesta por un discurso que interrelacione los distintos ordenamientos jurídicos con el objeto de reforzar las transformaciones en los países latinoamericanos. Así, el enfoque tiene el potencial de convertirse en un verdadero proyecto.

El Ius Constitutionale Commune en América Latina se apoya en los elementos de cercanía cultural y la historia jurídica compartida de la región, la cual es producto de la colonización ibérica, la influencia del Corpus Iuris Civilis y del Corpus Canonici, la Constitución de los Estados Unidos, la Constitución de Cádiz y el derecho constitucional y administrativo francés, así como en el ideal de una gran unión latinoamericana y su consiguiente fracaso. El ICCAL lucha, en consonancia y cooperación con actores en otros sistemas sociales, contra problemas compartidos, en particular la desigualdad y la exclusión de amplios sectores de la sociedad, el legado de los gobiernos autoritarios, la sombra de intereses norteamericanos, el hiperpresidencialismo, así como la frecuente debilidad del derecho. Existe además amplio consenso respecto del

172 A. Dyèvre. Game Theory and Judicial Behaviour. En J. Stelmach y W. ZaŁuski, coords. Game Theory and the Law. Cracovia. Copernicus Center Press, 2011. Disponible en: http://papers.ssrn.com/sol3/papers.cfm?abstract_id=1783507 La reacción del tribunal supremo venezolano apunta en esta dirección, op cit. 146.

173 L. Burgorgue-Larsen, coord. Les interactions normatives. Droit de l'Union européenne et droit international. Paris: Pedone, 2012.

174 La Fundación Konrad Adenauer también comparte esta visión y la fomenta al organizar encuentros entre los mencionados tribunales. 
camino a tomar. Los mecanismos de integración económica son considerados poco prometedores. La esperanza yace más bien en un constitucionalismo de raíces regionales basado en derechos humanos con protección supraestatal.

¿Cuáles son las perspectivas de este Ius Constitutionale Commune en América Latina? El que busque razones para el desaliento las encontrará, ya sea en los recorridos históricos, rasgos culturales, estructuras económicas, circunstancias geopolíticas, relaciones de poder, conflictos sociales, sean lo que sean. Razones abundan. Empero: visto en su conjunto y a pesar de todas estas dificultades, el constitucionalismo transformador latinoamericano es expresión de una dinámica tan impactante que hasta un realista puede apostar por él.

\section{BIBLIOGRAFÍA}

Abramovich, V. y Courtis, C. Los derechos sociales como derechos exigibles. Madrid: Trotta, 2002.

Aguilar Cavallo, G. Emergencia de un derecho constitucional común en material de pueblos indígenas. En Bogdandy, A. v., Ferrer Mac-Gregor, E. y Morales AntoniazzI, M., coords. La Justicia Constitucional y su internacionalización. Hacia un Ius Constitutionale Commune en América Latina? Vol. 2. México D.F.: unAm, 2010, 3-84.

Ahumada, C. Comercio, género y propiedad intelectual: trc entre Estados Unidos y Colombia. En Girón, A., coord. Género y Globalización. Buenos Aires: Clasco, 2009, 165-188.

Alvarez, A., Latin America and International Law. American Journal of International Law. 1909, 3(2), 269-353.

Arango, R. Fundamentos del Ius Constitutionale Commune en América Latina: Derechos Fundamentales, Democracia y Justicia Constitucional. En Bogdandy, A. v., FiX-Fierro, H. y Morales Antoniazzi, M., coords., Ius Constitutionale Commune en América Latina. Rasgos, potencialidades y desafíos. México: unAm, 2014, 25-36.

Arango, R. Derechos, constitucionalismo y democracia. Bogotá: Universidad Externado Colombia, 2004.

Ayala Corao, C. La doctrina de la "inejecución" de las sentencias internacionales en la jurisprudencia constitucional de Venezuela (1999-2009). En Bogdandy, A. v., Ferrer Mac-Gregor, E. y Morales Antoniazzi, M., coords., La Justicia Constitucional y su internacionalización. Hacia un Ius Constitutionale Commune en América Latina? Vol. 2. México D.F.: UnAM, 2010, 85-157.

Barroso, J. Discurso sobre el estado de la Unión 2013, Sesión plenaria del Parlamento Europeo, Estrasburgo, 11 de setiembre de 2013. Disponible en: http://europa.eu/rapid/ press-release_SPEECH-13-684_es.htm

Base de datos sobre tratados comerciales de la OMC. Organización Mundial de Comercio. Disponible en: http://rtais.wto.org/UI/PublicSearchByMemberResult.aspx?MemberC ode $=152 \&$ lang $=1 \&$ redirect $=1$ 
BAZÁN, V. La integración supranacional y el federalismo en interacción: perspectivas y desafíos. Anuario de Derecho Constitucional Latinoamericano. 2009, 15, 639-687.

Becker LorcA, A. International Law in Latin America or Latin American International Law? Rise, Fall, and Retrieval of a Tradition of Legal Thinking and Political Imagination. Harvard International Law Journal. 2006, 47, 283-305.

Benda-Beckmann, F. v. Who's Afraid of Legal Pluralism? J. Legal Pluralism \& Unofficial L. 2002, 47, 37-82.

Benhabib, S. The Philosophical Foundations of Cosmopolitan Norms. En Benhabib, S. y Post, R., coords. Another Cosmopolitanism. Oxford: oup, 2006, 13-44.

Bernstorff, J. v. Menschenrechte und Betroffenenrepräsentation. Entstehung und Inhalt eines UN-Antidiskriminierungsübereinkommens über die Rechte von behinderten Menschen. ZaöRV. 2007, 67, 1041-1063.

Binder, C. Auf dem Weg zum lateinamerikanischen Verfassungsgericht? Die Rechtsprechung des Interamerikanischen Menschenrechtsgerichtshofs im Bereich der Amnestien. ZaöRV. 2011, 71, 1-29.

Bogdandy, A. v. y Hinghofer-Szalkay, S. Das etwas unheimliche Ius Publicum Europaeum. Begriffsgeschichtliche Analysen im Spannungsfeld von europäischem Rechtsraum, droit public de l'Europe und Carl Schmitt. ZaöRV. 2013, 73(2), 209-248.

Bogdandy, A. v. y IoAnnidis, M. La deficiencia sistémica en el Estado de Derecho. Qué es, qué se ha hecho y qué se puede hacer. Revista de Estudios Políticos. 2014, 165, 19-64.

Bogdandy, A. v. y Venzke, I. In whose Name? A Public Law Theory of Adjudication. Oxford: Oxford University Press, 2014.

Bogdandy, A. v., Fix-Fierro, H. y Morales Antoniazzi, M., coords. Construcción y papel de los derechos sociales fundamentales. Hacia un ius constitucionale commune en América Latina, México, unam, 2011.

Bogdandy, A. v., Fix-Fierro, H. y Morales Antoniazzi, M., coords. Ius Constitutionale Commune en América Latina. Rasgos, potencialidades y desafios, México D.F.: UNAM, 2014.

Braig, M., Costa, S. y Göbel, B. Soziale Ungleichheiten und globale Interdependenzen in Lateinamerika. Eine Zwischenbilanz. desiguALdades.net (online), Berlín, Working Paper Series 4, 2013. Disponible en: www.desigualdades.net/Resources/Working_Paper/4_WP_Braig_Costa_G__bel_Online.pdf?1371216108

Brewer-Carías, A. Constitutional Protection of Human Rights in Latin America. A Comparative Study of Amparo Proceedings. Nueva York: cup, 2014.

Brewer-Carías, A. Crónica sobre la "in" justicia constitucional. La Sala Constitucional y el autoritarismo en Venezuela. Caracas: Jurídica Venezolana, 2007.

BRICEÑo RUIZ, J. Ejes y modelos en la etapa actual de la integración económica regional en América Latina. Estudios internacionales (online), Santiago, agosto de 2013, 45(175), 9-39. Disponible en: http://www.scielo.cl/pdf/rei/v45n175/art01.pdf 
Burgorgue-Larsen, L., coord. Les interactions normatives. Droit de l'Union européenne et droit international. Paris: Pedone, 2012.

Burgorgue-Larsen, L. y Úbeda de Torres, A. The Inter-American Court of Human Rights. Case Law and Commentary. Traducido por Rosalind Greenstein. Oxford: oup, 2011.

Burgorgue-Larsen, L. La Corte Interamericana de Derechos Humanos como tribunal constitucional. En Bogdandy, A. v., FiX-Fierro, H. y Morales Antoniazzi, M., coords. Ius Constitutionale Commune en América Latina. Rasgos, potencialidades y desafíos. México D.F.: unAm, 2014, 421-458.

Burgourge, L. y Úbeda de Torres, A. The Inter-American Court of Human Rights: Case Law and Commentary. Oxford: oup, 2011.

Bustos Gisbert, R. Pluralismo constitucional y diálogo jurisprudencial. México D.F.: Porrúa, 2012.

Calvo, C. Derecho internacional teórico y práctico de Europa y América. Vol. 1. Paris: D'Amyot, 1868.

Cançado Trindade, A. A. International Law for Humankind. Towards a New Jus Gentium (I). Recueil des cours. T. 316 (2005), 9-439; International Law for Humankind. Towards a New Jus Gentium (II). Recueil des cours. T. 317 (2005), 9-312.

CApaldo, G., Siekmann, J. y Clérico, L., coords. Internacionalización del derecho constitucional, constitucionalización del derecho internacional. Buenos Aires: Eudeba, 2012.

Cardosos, E. Litígio Estratégico e Sistema Interamericano de Direitos Humanos. Belo Horizonte: Forum, 2012.

Carpizo, J. Perspectiva de la protección de los derechos humanos en el México de 2010. En Fix-Zamudio, H. y Valadés, D., coords. Formación y perspectivas del Estado latinoamericano en derechos humanos y en México, México D.F.: unam, 2010, 98 et seq.

Carpizo, J. Concepto de democracia y sistema de gobierno en América Latina. México D.F.: UNAM, 2007.

Carpizo, J. Das mexikanische Präsidialsystem. Múnich: Eberhard, 1987.

CArpizo, J. El presidencialismo mexicano. México: Siglo xxi Editores, 1979.

Casal Hernández, J. M. El constitucionalismo latinoamericano y la oleada de reformas constitucionales en la región andina. Rechtsgeschichte. 2010, 16, 212-241.

Casal Hernández, J. M. Las restricciones al ejercicio de los derechos humanos y la cláusula de la sociedad democrática en el sistema interamericano. En SaIz Arnaiz, A., Morales Antoniazzi, M. y Ugartemendia, J., coords. Las implicaciones constitucionales de los procesos de integración. Oñate: Instituto Vasco de Administración Pública, 2011, 477-505.

CASSESE, A. Y a-t-il un conflit insurmontable entre souveraineté des États et justice pénale internationale? En Cassese, M. y Delmas-Marty, M., coords. Crimes internationaux et juridictions internationales. Paris : Presses Universitaires de France, 2002, 13-29. 
CASSESE, S. I Tribunali di Babele. I giudici alla ricerca di un nuovo ordine globale. Roma: Donzelli, 2009.

Cavallaro, J. L. y Schaffer, E. J. Less as More: Rethinking Supranational Litigation of Economic and Social Rights in the Americas. Hastings Law Journal. 2004, 56(2), 217-282.

Cepeda M. J. La defensa judicial de la Constitución. La gran fortaleza colombiana. En Bogdandy, A. v., Piovesan, F. y Morales Antoniazzi, M., coords. Direitos Humanos, Democracia e Intregração Jurídica na América do Sul. Rio de Janeiro: Lumen Juris, 2009, 581-628.

Cepeda, M. J. ¿Cómo se hizo la Asamblea Constituyente? En Cepeda, M. J., Introducción a la Constitución de 1991: hacia un nuevo constitucionalismo. Bogotá: Presidencia de la República, 1993, 73-186.

Cepeda, M. J. Los derechos fundamentales de la Constitución de 1991. Vol. 2. Bogotá: Temis, 1997.

Clérico, L. y Alado, M. De la inclusión como igualdad en clave de redistribución y reconocimiento. Rasgos, potencialidades y desafíos para el derecho constitucional interamericano. En Bogdandy, A. v., Fix-Fierro, H. y Morales Antoniazzi, M., coords., Ius Constitutionale Commune en América Latina. Rasgos, potencialidades y desafíos. México: unam, 2014, 219-264.

Clérico, L. El examen de proporcionalidad en el derecho constitucional. Buenos Aires: Universitaria de Buenos Aires, 2009.

Clerico, L., Sieckmann, J. R. y Oliver-Lalana, D. Prólogo. En Clérico, L., coord., Derechos fundamentales, principios y argumentación: Estudios sobre la teoría jurídica de Robert Alexy. Granada: Comares, 2011, vII-VIII.

CoING, H. Die europäische Privatrechtsgeschichte der neueren Zeit als einheitliches Forschungsgebiet. Probleme und Aufbau. Ius Commune. 1967, 1, 1-33.

Comaroff, J. y Comaroff, J. Theory from the South. Or, how Euro-America is Evolving Toward Africa. Boulder: Paradigm, 2012.

Corte Constitucional de Colombia, C-141 de 26 de febrero de 2010.

Corte Interamericana de Derechos Humanos. Almonacid Arellano vs. Chile, Sentencia de 26 de setiembre de 2006, Serie C, n. ${ }^{\circ} 154$.

Corte Interamericana de Derechos Humanos. Barrios Altos (Chumbipuma Aguirre y otros vs. Perú), Fondo, Sentencia de 14 de marzo de 2001, Serie C, n. ${ }^{\circ} 75$.

Corte Interamericana de Derechos Humanos. Almonacid Arellano y otros vs. Chile, Excepciones Preliminares, Fondo, Reparaciones y Costas, Sentencia de 26 de septiembre de 2006 , Serie C n. ${ }^{\circ} 154$.

Corte Interamericana de Derechos Humanos. Cabrera García y Montiel Flores vs. México, Excepción Preliminar, Fondo, Reparaciones y Costas, Sentencia de 26 de 
noviembre de 2010, Serie C, n. ${ }^{\circ} 220$, Voto razonado del juez ad hoc Eduardo Ferrer Mac-Gregor Poisot.

Corte Interamericana de Derechos Humanos. La Cantuta vs. Perú, Interpretación de la Sentencia de Fondo, Reparaciones y Costas, Sentencia de 30 de noviembre de 2007, Serie C n. ${ }^{\circ} 173$.

Corte Interamericana de Derechos Humanos. Comunidad Mayagna (Sumo) Awas Tigni) vs. Nicaragua, Fondo, Reparaciones, y Costas, Sentencia de 31 de agosto de 2000 Serie C, n. ${ }^{\circ} 66$.

Corte Interamericana de Derechos Humanos. Comunidad indígena Yakye Axa vs. Paraguay, Sentencia de 17 de junio de 2005, Serie C, n. ${ }^{\circ} 125$

Corte Interamericana de Derechos Humanos. Gomes Lund y otros ("Guerrilha do Araguaia") vs. Brasil, Excepciones Preliminares, Fondo, Reparaciones y Costas, Sentencia de 24 de noviembre de 2010, Serie C n. ${ }^{\circ} 219$.

Corte Interamericana de Derechos Humanos. Gelman vs. Uruguay, Fondo y Reparaciones, Sentencia de 24 de febrero de 2011, Serie C n. 221

Corte Interamericana de Derechos Humanos. González y otras ("Campo Algodonero") vs. México, Excepción Preliminar, Fondo, Reparaciones y Costas, Sentencia de 16 de noviembre de 2009 , Serie C, n. 205.

Corte Interamericana de Derechos Humanos. Las Niñas Yean y Bosico vs. República Dominicana, Excepciones Preliminares, Fondo y Reparaciones, Sentencia de 8 de setiembre de 2005, Serie C, n. ${ }^{\circ} 130$.

Corte Interamericana de Derechos Humanos. Los "Niños de la Calle" (Villagrán Morales y otros) vs. Guatemala, Fondo, Sentencia de 19 de noviembre de 1999, Serie C, n. ${ }^{\circ} 63$.

Corte Interamericana de Derechos Humanos. González y otras ("Campo Algodonero") vs. México, Excepción Preliminar, Fondo, Reparaciones y Costas, Sentencia de 16 de noviembre de 2009 , Serie C, n. ${ }^{\circ} 205$.

Corte Interamericana de Derechos Humanos. Opinión Consultiva OC-16/99, solicitada por los Estados Unidos Mexicanos, sobre "El derecho a la información sobre la asistencia consular en el marco de las garantías del debido proceso legal", Opinión Consultiva de 1 de octubre de 1999, Serie A, n. ${ }^{\circ} 16$.

Corte Interamericana de Derechos Humanos. Velásquez Rodríguez vs. Honduras, Fondo, Sentencia de 29 de julio de 1988 , Serie C, n. ${ }^{\circ} 4$.

Corte Permanente de Justicia Internacional. S.S. Lotus, Francia vs. Turquía, Sentencia de 7 de noviembre de 1927, Serie A, n. ${ }^{\circ} 10$.

Corte Suprema, Sala Constitucional, exp.08-1572, Sentencia de 18 de diciembre de 2008.

Currie, D. P. The Constitution in the Supreme Court: The Second Century 1888-1986. Chicago/Londres: University of Chicago Press, 1990. 
Davis, M. C. Constitutionalism and Political Culture. Harvard Human Rights Journal. 1998, 11, 109-147.

DE Vergottini, G. Premessa. En Mezzetti, L. y Ferrer Mac-Gregor, E., coords. Diritto processuale costituzionale. Omaggio italiano a Héctor Fix-Zamudio per i suoi 50 anni di ricercatore di diritto. Milán: CEDAM, 2010, 3-5.

Delmas-Marty, M. Trois défis pour un droit mondial. Paris: Seuil, 1998.

Di Plinio, G. Rule of law/fazhi: il diritto in Cina tra wto e Asian values. Diritto pubblico comparato ed europeo. 2011, 2, 326-338.

Domingo, R. The New Global Law. Cambridge: cup, 2010.

Draude, A. y Neuweiler, S. Governance in der postkolonialen Kritik. Die Herausforderung lokaler Vielfalt jenseits der westlichen Welt. ${ }_{F B}$-Governance Working Paper Series. 2010, 25(5), 7-8.

Dulitzky, A. When Afro-Descendants Became Tribal Peoples. uCLA Journal of International Law and Foreign Affairs. 2010, 15, 29-82.

Duve T. Verfassung und Verfassungsrecht in Lateinamerika im Licht des bicentenario. Einleitung zur Debatte. Rechtsgeschichte. 2010, 16, 16-18.

Duve T. Von der Europäischen Rechtsgeschichte zu einer Rechtsgeschichte Europas in globalhistorischer Perspektive. Rechtsgeschichte. 2012, 20, 18-71.

Duve T. Internationalisierung und Transnationalisierung der Rechtswissenschaft - aus deutscher Perspective. LOEWE Research Focus "Extrajudicial and Judicial Conflict Resolution”. Working Paper 2013, 6, 1-17.

Dworkin, R. Hard Cases. Harvard Law Review. 1975, 88(6), 1057-1109.

Dyèvre, A. Game Theory and Judicial Behaviour. En Stelmach J. y ZaŁuski, W., coords. Game Theory and the Law. Cracovia: Copernicus Center Press, 2011, 115-144.

ElíAs, J. S. Constitutional Changes, Transitional Justice and Legitimacy: The Life and Death of Argentina's “Amnesty Laws”. Student Scholarship Papers, Paper 57.

Elsner, G. y Huber, R. Prólogo. Anuario de Derecho Constitucional Latinoamericano, 2011, 9-11.

Escobar García, C. La defensa judicial de la Constitución en el constitucionalismo colombiano. Balances y perspectivas después de dos décadas. Foro Revista de Derecho. 2009, 12, 127-180.

Esquirol, J. L. Latin America. En Fassbender, B. y Peters, A., coords. The Oxford Handbook of the History of International Law. Oxford: oup, 2013, 553-577.

Ferreira Mendes, G. y Rufino do Vale, A. O pensamento de Peter Häberle na jurisprudência do Supremo Tribunal Federal. Observatório da Jurisdição Constitucional, 2008-2009, 2, 2 ss. 
Ferrer Mac-Gregor, E. Hacia la formación jurisprudencial interamericana de un Ius Constitutionale Commune Americanum. Eficacia de la sentencia interamericana y la cosa juzgada internacional (Sobre el cumplimiento del Caso Gelman vs. Uruguay). En Bogdandy, A. v., Fix-Fierro, H. y Morales Antoniazzi, M., coords. Ius Constitutionale Commune en América Latina. Rasgos, potencialidades y desafíos. México D.F.: UNAM, 2014, 329-382.

Ferrer Mac-Gregor, E. Semblanza del Maestro Héctor Fix-Zamudio. En Ferrer MacGregor, E. y Zaldívar Lelo de LarRea, A., coords., La ciencia del derecho procesal constitucional. Estudios en homenaje a Héctor Fix-Zamudio en sus cincuenta años como investigador del derecho. México: UnAM, 2008, XXXV-XL.

Ferrer Mac-Gregor, E. Panorámica del Derecho procesal constitucional y convencional. Madrid: Pons, 2013.

Fiallos Oyanguren, M. Los organismos electorales en el proceso de consolidación democrática en América Latina. En Pretelt, J. y Ramírez J. M., comps., Democracia política y electoral en América Latina, Bogotá, Universidad Sergio Arboleda, oEA, 2000, 348 ss.

Fix Zamudio, H. El derecho internacional de los derechos humanos en las Constituciones latinoamericanas y en la Corte Interamericana de Derechos Humanos. Revista Latinoamericana de Derecho. 2004, 1, 141-180.

Fix-Fierro, H. y López-Ayllón, S. The Impact of Globalization on the Reform of the State and the Law in Latin America. Traducido por Virginia Davis. Houston Journal of International Law. 1996-1997, 19, 785-805.

Fix-Fierro, H. Epílogo. En Bogdandy, A. v., Fix-Fierro, H. y Morales Antoniazzi, M., coords., Ius Constitutionale Commune en América Latina. Rasgos, potencialidades y desafíos. México D.F.: unAm, 2014, 501-504.

FIX-Fierro, H. Los juristas académicos del Instituto de Investigaciones Jurídicas de la UNAm y la construcción de las nuevas instituciones democráticas. En VÁzQuez Ramos, H., coord., Cátedra Nacional de Derecho Jorge Carpizo. Reflexiones Constitucionales. México: unam, 2014, 451-459.

Fix-Zamudio, H. La creciente internacionalización de las Constituciones iberoamericanas, especialmente en la regulación y protección de los derechos humanos. En MAC-GrEGOR, E. y Morales Antoniazzi, M., coords., La Justicia Constitucional y su Internacionalización. Hacia un Ius Constitutionale Commune en América Latina? Vol. 2. México D.F.: UNAM, 2010, 583-673.

Foblets, M. Diversité Religieuse en Europe: Une Approche Innovante Conjuguant l'Approche Juridique et Sociologique. En Ast, F. y Duarte, B., coords., Les Discriminations Religieuses en Europe: Droit et Pratiques. Paris: L'Harmattan, 2012, 103-117.

Frank, A. G. ReOrient. Global Economy in the Asian Age. Berkeley/Los Angeles: University of California Press, 1998.

García Ramírez, S. El control judicial interno de convencionalidad. IUS. Revista del Instituto de Ciencias Jurídicas de Puebla. 2011, 5(28), 123-159. 
García Ramírez, S. Foreword. En Burgorgue-Larsen, L. y Úbeda de Torres, A. The Inter-American Court of Human Rights: Case-Law and Commentary. Oxford: Oxford University Press, 2011, xvii-xxviii.

García Ramírez, S. La "Navegación Americana" de los Derechos Humanos: Hacia un Ius Commune. En Bogdandy, A. v., Fix-Fierro, H. y Morales Antoniazzi, M., coords., Ius Constitutionale Commune en América Latina. Rasgos, potencialidades y desafíos. México D.F.: unAM, 2014, 459-491.

García Villegas, M. Ineficacia del derecho y cultura del incumplimiento de reglas en América Latina. En Rodríguez Garavito, C. El derecho en América Latina. Un mapa para el pensamiento jurídico del siglo XXI. Buenos Aires: Siglo XXI Editores, 2011, 161-184.

Gargarella, R. El "nuevo constitucionalismo latinoamericano. El País (online), Madrid. 20 de agosto de 2014. Vol. 20. Disponible en: http://elpais.com/elpais/2014/07/31/ opinion/1406816088_091940.html

Gargarella, R. Sin lugar para la soberanía popular. Democracia, derechos y castigo en el caso Gelman. Seminario de Latinoamérica de Teoría Constitucional y Política de la Universidad de Yale (online), 2013.

Gargarella, R. Latin American Constitutionalism 1810-2010. The Engine Room of the Constitution. Oxford: oup, 2013.

Gaviria Trujillo, C. Presentación. Honores y Justicia al Juez Fix-Zamudio. En Gaviria Trujillo, C., coord., Liber amicorum Héctor Fix-Zamudio. Vol. 1. San José: Secretaría de la Corte Interamericana de Derechos Humanos, 1998, XLIX-LII.

Girón, A. Financiamiento del desarrollo. Endeudamiento externo y reformas financieras. En Vidal, G. y Guillén, R. A., coords., Repensar la teoría del desarrollo en un contexto de Globalización. Homenaje a Celso Furtado. Buenos Aires: Clasco, 2007, 125-142.

Góngora Mera, M. La difusión del bloque de constitucionalidad en la jurisprudencia latinoamericana y su potencial en la construcción del ius constitutionale commune latinoamericano. En Bogdandy, A. v., Fix-Fierro, H. y Morales Antoniazzi, M., coords., Ius Constitutionale Commune en América Latina. Rasgos, potencialidades y desafíos. México D.F.: unAm, 2014, 301-328.

Góngora Mera, M. Inter-American Judicial Constitutionalism. On the Constitutional Rank of Human Rights Treaties in Latin America through National and Inter-American Adjudication. San José: Inter-American Institute for Human Rights, 2011.

Góngora Mera, M.; Herrera, G. y Müller, C. The Frontiers of Universal Citizenship. Transnational Social Spaces and the Legal Status of Migrants in Ecuador. desiguALdades.net (online). Berlin, Working Paper Series 71, 2014, 13 ss. Disponible en: http:// www.desigualdades.net/Resources/Working_Paper/71-WP-Gongora-Mera-HerreraMueller-Online.pdf?1396440530

GonzÁlez Quevedo, J. Bases jurídicas para el empoderamiento político en los actuales diseños constitucionales de Venezuela, Ecuador y Bolivia. En Viciano Pastor R., coord., Estudios sobre el nuevo Constitucionalismo latinoamericano. Valencia: Tirant lo Blanch, 2012, 269-289. 
González, M. d. R. El periodo colonial y su legado. En Bogdandy, A. v., Fix-Fierro, H. y Morales Antoniazzi, M., coords., Ius Constitutionale Commune en América Latina. Rasgos, potencialidades y desafíos. México D.F.: unAm, 2014, 85-106.

Gordillo, A. et al. Derechos Humanos. Vol. 5. Buenos Aires: Fundación de Derecho Administrativo, 2005.

Grote, R. Los esfuerzos integradores en el contexto histórico suramericano. En Bogdandy, A. v., Landa Arroyo, C. y Morales Antoniazzi, M., coords., Integración suramericana a través del Derecho? Un análisis interdisciplinario y multifocal. Madrid: Centros de Estudios Políticos y Constitucionales, 2009, 3-22.

Günther, K. The Legacies of Injustice and Fear: A European Approach to Human Rights and their Effects on Political Culture. En Alston, P., coord., The EU and Human Rights. Oxford: oup, 1999, 117-146.

Habermas, J. Der gespaltene Westen: Kleine politische Schriften. Frankfurt am Main: Suhrkamp, 2004.

Habermas, J. Zur Verfassung Europas. Ein Essay. Berlin: Suhrkamp, 2011.

Hirschl, R. Towards Juristocracy. The Origins and Consequences of the New Constitutionalism. Cambridge: Harvard University Press, 2004.

Hofmann, M. Von der Transformation zur Kooperationsoffenheit? Die Öffnung der Rechtsordnungen ausgewählter Staaten Mittel- und Osteuropas für das Völker- und Europarecht. Berlín/Heidelberg: Springer, 2009.

Huhle, R. Lateinamerika und die Entstehung des internationalen System des Menschenrechtsschutzes. Nürnberg: Nürnberger Menschenrechtszentrum, 2007.

Instituto para la Integración de América Latina. Editorial. Derecho de la Integración: Revista Jurídica Latinoamericana. 11967, 1, 1, 5-7.

The International Society of Public Law, página web. Disponible en: http://icon-society.org/

Isiksel, T. Global legal pluralism as fact and norm. Global Constitutionalism. 2013, 2, 160-195.

Issacharoff, S. Fragile Democracies: Constitutional Courts in the Breach, 2014 (en prensa).

Jaramillo, J. Los órganos electorales supremos. En Nohlen, D. et. al., comps., Tratado de derecho electoral comparado de América Latina. Vol. 2. México: IIDH, 2007, 371-436.

Jenks, C. W., The Common Law of Mankind. Londres: Stevens \& Sons, 1958.

Jessup, P. C. Transnational Law. New Haven: Yale University Press, 1956.

Kapur, A. Asian Values v. the Paper Tiger. Dismantling the Threat to Asian Values Posed by the International Criminal Court. Journal of International Criminal Justice. 2013, 11(5), 1059-1090.

Klare, K. Legal Culture and Transformative Constitutionalism. South African Journal on Human Rights. 1998, 14(1), 146-188. 
Кокотт, J. Das interamerikanische System zum Schutz der Menschenrechte. Berlin/Heidelberg: Springer, 1986.

Koskenniemi, M. Human Rights Mainstreaming as a Strategy for Institutional Power. Humanity. An International Journal of Human Rights, Humanitarianism, and Development. 2010, 1, 47-58.

Koskenniemi, M. The Politics of International Law. Oxford: Hart, 2011.

Luhmann, N. Das Recht der Gesellschaft. Frankfurt am Main: Suhrkamp, 1993.

Malamud, A. El contexto del diálogo jurídico interamericano: fragmentación y diferenciación en sociedades más prosperas. En Bogdandy, A. v., Fix-Fierro, H. y Morales Antoniazzi, M., coords., Ius Constitutionale Commune en América Latina. Rasgos, potencialidades y desafíos. México: UnAM, 2014, 107-124.

Martínez Ruano, P. Los modelos latinoamericanos y europeos de control electoral. Revista Derecho Electoral. 2002, 13, 180-181.

Mendes, C. H. Constitutional Courts and Deliberative Democracy. Oxford: oup, 2013.

Merton, R. K., Auf den Schultern von Riesen: Ein Leitfaden durch das Labyrinth der Gelehrsamkeit. Frankfurt am Main: Suhrkamp, 1983.

Mohnhaupt, H. Historische Vergleichung im Bereich von Recht und Staat. Frankfurt am Main: Klostermann, 2000.

Morales Antoniazzi, M. El Estado abierto como objetivo del Ius Constitutionale Commune. Aproximación desde el impacto de la Corte Interamericana de Derechos Humanos. En Bogdandy, A. v., Fix-Fierro, H. y Morales Antoniazzi, M., coords., Ius Constitutionale Commune en América Latina. Rasgos, potencialidades y desafíos. México: UNAM, 2014, 265-299.

Morales Antoniazzi, M. Protección supranacional de la democracia en Suramérica. Un estudio sobre el acervo del ius constitutionale commune. México: unAM, 2014 (en prensa).

Muñoz Cifuentes, E. El constitucionalismo de la pobreza. Revista Xurídica da Universidade de Santiago de Compostela. 1995, 4(2), 53-78.

Neves, M. La concepción del estado de derecho y su vigencia prática en Suramerica. En Bogdandy, A. v., Landa Arroyo, C. y Morales Antoniazzi, M., coords., Integración suramericana a través del Derecho? Un análisis interdisciplinario y multifocal. Madrid, Centros de Estudios Políticos y Constitucionales, 2009, 51, 51-78.

Neves, M. Transconstitucionalismo. São Paulo: wmF Martins Fontes, 2009.

Neves, M. Verfassung und Positivität des Rechts in der peripheren Moderne. Eine theoretische Betrachtung und Interpretation des Falls Brasilien. Berlin: Duncker und Humblot, 1992.

Nikken, P. El Derecho Internacional de los Derechos Humanos. Revista de la Facultad de Ciencias Jurídicas y Políticas. 1989, 72, 15-52. 
Nogueira Alcalá, H. Diálogo interjurisdiccional, control de convencionalidad y jurisprudencia del Tribunal Constitucional en período 2006-2011. Estudios Constitucionales. 2012, 10(2), 57-140.

Nohlen, D. Caudillismo, /nacionalismo e integración. En Bogdandy, A. v., Landa Arroyo, C. y Morales Antoniazzi, M., coords., Integración suramericana a través del Derecho? Un análisis interdisciplinario y multifocal. Madrid: Centros de Estudios Políticos y Constitucionales, 2009, 35-50.

Nohlen, D. Demokratie ohne Vertrauen: Herausforderung für die Zivilgesellschaft in Lateinamerika. Internationale Politik und Gesellschaft, 2004, 80-106.

Nolte, D. y Schilling-Vacaflor, A., coords. New Constitutionalism in Latin America. Promises and Practices. Farnham: Ashgate, 2012.

Novoa Monreal, E. El derecho como obstáculo al cambio social. México/Buenos Aires: Siglo XXI Editores, 1980.

O'Donnel, D. Derecho Internacional de los Derechos Humanos. Normativa, jurisprudencia y doctrina de los sistemas universal e interamericano. Bogotá: Oficina en Colombia del Alto Comisionado de las Naciones Unidas para los Derechos Humanos, 2004.

Oeter, S. (Fragile) Staatlichkeit und Entwicklung. En Dann, P., Kadelbach, S. y KaltenBORN, M., coords., Entwicklung und Recht. Baden-Baden: Nomos, 471-497.

Osuna, N. Panorama de la justicia constitucional colombiana. En Bogdandy, A. v., Ferrer Mac-Gregor, E. y Morales Antoniazzi, M., coords., La Justicia Constitucional y su Internacionalización. Vol. 1. México D.F.: UNAM, 2010, 623-643.

Pampillo Baliño, J. P. The legal integration of the American continent: an invitation to legal science to build a new ius commune. ILSA Journal of International \& Comparative Law. 2011, 17(3), 517-533.

Parra Vera, O. El impacto de las decisiones interamericanas. Notas sobre la producción académica y una propuesta de investigación en torno al empoderamiento institucional. En Bogdandy, A. v., Fix-Fierro, H. y Morales Antoniazzi, M., coords., Ius Constitutionale Commune en América Latina. Rasgos, potencialidades y desafíos. México D.F.: UNAM, 2014, 383-420.

PARra, O. Lucha contra la impunidad, independencia judicial y derechos de los pueblos indígenas. Algunos avances y debates en torno a la jurisprudencia de la Corte Interamericana de Derechos Humanos. En Rey Martínez, F., coord. Los derechos en Latinoamérica: tendencias judiciales recientes. Madrid: Complutense, 2012, 363-416.

Peters, A. Realizing Utopia as a Scholarly Endeavour. EJIL. 2013, 24, 533-552.

Piovesan, F. Direitos humanos e diálogo entre jurisdições. Revista Brasileira de Direito Constitucional. 2012, 19, 67-93.

Piovesan, F. Ius Constitutionale Commune impacto del sistema interamericano: Rasgos, potencialidades y desafíos. En Bogdandy, A. v., Fix-Fierro, H. y Morales Antoniazzi, M., coords., Ius Constitutionale Commune en América Latina. Rasgos, potencialidades y desafíos. México D.F.: unam, 2014, 61-84. 
Piovesan, F. Proteção dos direitos sociais: desafios do ius commune sul-americano. Revista do Tribunal Superior do Trabalho. 2011, 77(4), 102-139.

Piovesan, F. Direitos humanos e o direito constitucional internacional. São Paulo: Limonad, 1996.

Prada Alcoreza, R. Análisis de la nueva Constitución Política del Estado. Crítica y emancipación. Revista Latinoamericana de Ciencias Sociales. 2008, 1, 35-50.

Prebisch, R. Hacia una dinámica del desarrollo latinoamericano. México D.F.: Fondo de Cultura Económica, 1961.

Rincón-Covelli, T. El derecho internacional de los derechos humanos: ¿límite o elemento constitutivo de la democracia? -A propósito de la transición uruguaya a la democracia. Estudios Socio-Jurídicos. 2012, 14(2), 71-106.

Rivera Santibánez, J. A. La justicia constitucional en el nuevo modelo de Estado boliviano. En Mac-Gregor, E. y Morales Antoniazzi, M., coords., La Justicia Constitucional y su Internacionalización. Hacia un Ius Constitutionale Commune en América Latina? Vol. 1. México D.F.: unam, 2010, 645-680.

Rojas, R. El TLC: Poder y representación en el capitalismo contemporáneo. Colombia Internacional. 2005, 61, 116-133.

Roux, T. Transformative Constitutionalism and the best interpretation of the South African constitution: distinction without a difference? Stellenbosch Law Review. 2009, 20(2), 258-285.

Ruiz Fabri, H. y Rosenfeld, M., coords. Repenser le constitutionnalisme à l'âge de la mondialisation et de la privatisation. Paris: Société de législation comparée, 2011.

Saavedra Alessandri, P. y Pacheco Arias, G. Las sesiones "itinerantes" de la Corte Interamericana de Derechos Humanos: un largo y fecundo caminar por América. En GARCía Ramírez, S. y Castañeda Hernández, M., coords., Recepción nacional del derecho internacional de los derechos humanos y admisión de la competencia contenciosa de la Corte Interamericana. México D.F.: unAm, 2009.

SAGÜÉs, N. Obligaciones internacionales y control de convencionalidad. Estudios Constitucionales. 2010, 8(1), 117-136. Disponible en: http://www.scielo.cl/scielo.php?pid=S0718 52002010000100005\&script=sci_arttext $-\mathrm{n} 1 \# \mathrm{n} 1$

Schilling-Vacaflor, A. Recht als umkämpftes Terrain. Die neue Verfassung und indigene Völker in Bolivien. Baden-Baden: Nomos, 2010.

SEn, A. The Idea of Justice. Londres: Lane, 2009.

Serna de la Garza, J. M. El concepto del Ius Commune latinoamericano en derechos humanos: elementos para una agenda de investigación. En Bogdandy, A. v., Fix-Fierro, H. y Morales Antoniazzi, M., coords., Ius Constitutionale Commune en América Latina. Rasgos, potencialidades y desafíos. México D.F.: unam, 2014, 199-218.

Serna de la Garza, J. M. The Constitution of Mexico. A Contextual Analysis. Oxford: Hart, 2013. 
Serna de la Garza, J. M. El concepto del ius commune latinoamericano en derechos humanos: elementos para una agenda de investigación. En Bogdandy, A. v., FiX-Fierro, H. y Morales Antoniazzi, M., coords. Ius Constitutionale Commune en América Latina. Rasgos, potencialidades y desafíos. México D.F.: unam, 2014, 199-218.

Serna de la Garza, J. M. Impacto e implicaciones constitucionales de la globalización en el sistema jurídico mexicano. México D.F.: UnAm, 2012.

Sferrazza Taibi, P. ¿Amnistías democráticas? El Caso Gelman vs. Uruguay de la Corte Interamericana de Derechos Humanos: un caso práctico para una reflexión teórica. En Santano, S. A. y Mejías, S. A., coords., La seguridad, un concepto amplio y dinámico: V Jornadas de Estudios de Seguridad. Madrid: IUGM-Uned, 2013, 323-356.

Shany, Y. Assessing the Effectiveness of International Courts: A Goal-Based Approach. American Journal of International Law. 2012, 106(2), 225-270.

Sierra Cadena, G. d. J. La Justicia constitucional en la era de la gobernanza (Un análisis de perspectiva comparada desde la periferia del derecho). Universitas. Revista de Filosofía, Derecho y Política. 2011, 13, 67-95.

Sikкink, K. Reconceptualizing Sovereignty in the Americas: Historical Precursors and Current Practices. Houston Journal of International Law. 1996-1997, 19, 705-729.

Sissenich, B. Weak States, Weak Societies: Europe's East-West Gap. Acta Politica. 2010, 45(1-2), 11-40.

Sociedad Latinoamericana de Derecho Internacional. Página web, disponible en: http:// lasil-sladi.org/es/home.html

Stichwen, R., Inklusion und Exklusion. Studien zur Gesellschaftstheorie. Bielefeld: Transcript, 2005.

Tamanaha, B. Z. What is 'General' Jurisprudence? A Critique of Universalistic Claims by Philosophical Concepts of Law. Transnational Legal Theory. 2011, 2(3), 287-308.

Tamburini, F. Historia y destino de la "doctrina calvo": ¿actualidad u obsolescencia del pensamiento de Carlos Calvo? Revista de Estudios Histórico-Jurídicos. 2012, 24, 81-101.

Teitel, R. Transitional Justice Genealogy. Harvard Human Rights Journal. 2003, 16, 69-94.

Teitel, R. Transitional justice. Oxford: oup, 2000.

Tramontana, E. La participación de las ong en el Sistema Interamericano de Protección de los Derechos Humanos: avances, desafíos y perspectivas. En Bogdandy, A. v., Ferrer Mac-Gregor, E. y Morales Antoniazzi, M., coords., La Justicia Constitucional y su Internacionalización. Vol. 2. México D.F.: UNAM, 2010, 533-556.

Upegui Mejía, J. C. Cuatro indicios de la influencia de la Declaración Universal de los Derechos Humanos de 1948 en el constitucionalismo colombiano. Revista Derecho del Estado. 2009, 23, 191-212.

VALADÉs, D. Formación y transformación del sistema presidencial en América Latina: Una reflexión sobre el ius commune latinoamericano. En Bogdandy, A. v., Fix-Fierro, H. y 
Morales Antoniazzi, M., coords., Ius Constitutionale Commune en América Latina. Rasgos, potencialidades y desafíos. México D.F.: unam, 2014, 169-198.

Valadés, D. Palabras de Bienvenida. Revista Latinoamericana de Derecho Social. 2005, 1, IX-XIII.

VAladÉs, D. Peter Häberle: un jurista para el siglo XXI. Estudio introductorio. En Häberle, P., El Estado constitucional. México D.F.: UnAM, 2001, XXI-LXXXIV.

Ventura, A. Presentación. Revista Latinoamericana de Derecho. 2004, 1, XI-X.

Viciano PAStor, R., coord. Estudios sobre el nuevo Constitucionalismo Latinoamericano. Valencia: Tirant lo Blanch, 2012.

Vogel, K. Die Verfassungsentscheidung des Grundgesetzes für die internationale Zusammenarbeit. Tübingen: Mohr, 1964.

WALKer, N. The Idea of Constitutional Pluralism. Modern Law Review. 2002, 65, 317-359.

WeILer, J. The International Society for Public Law - Call for Papers and Panels. Int. J. Constitutional Law. 2014, 12, 1-3.

Wendel, M. Permeabilität im europäischen Verfassungsrecht. Verfassungsrechtliche Integrationsnormen auf Staats- und Unionsebene im Vergleich. Tübingen: Mohr Siebeck, 2011.

Wendt, H. y Renn, J. Knowledge and Science in Current Discussions of Globalization. En RENN J., coord., The Globalization of Knowledge in History. Berlin: Edition Open Access, 2012, 45-72.

Worldwide Governance Indicators. Banco Mundial, 2014. Palabra clave: rule of law, 2012. Disponible en: http://info.worldbank.org/governance/wgi/index.aspx\#home

World Justice Project, 2014 Disponible en: http://worldjusticeproject.org/sites/default/files/ files/wjp_rule_of_law_index_2014_report.pdf

XI Congreso Iberoamericano de Derecho Constitucional "Jorge Carpizo", 17-19 de septiembre de 2013 en Tucumán, Argentina. Disponible en: http://www.iberoconstitucional.com.ar/

Zimmermann, R. Das römisch-kanonische ius commune als Grundlage europäischer Rechtseinheit. Juristenzeitung. 1992, 8-20. 